\title{
ROSA/LSTF Tests and RELAP5 Posttest Analyses for PWR Safety System Using Steam Generator Secondary-Side Depressurization against Effects of Release of Nitrogen Gas Dissolved in Accumulator Water
}

\author{
Takeshi Takeda, ${ }^{1}$ Akira Ohnuki, ${ }^{2}$ Daisuke Kanamori, ${ }^{3}$ and Iwao Ohtsu ${ }^{1}$ \\ ${ }^{1} J a p a n$ Atomic Energy Agency, 2-4 Shirakata-Shirane, Tokai-mura, Naka-gun, Ibaraki-ken 319-1195, Japan \\ ${ }^{2}$ Mitsubishi Heavy Industries, Ltd., 1-1 Wadasaki 1-Chome, Hyogo-ku, Kobe-shi, Hyogo-ken 652-8585, Japan \\ ${ }^{3}$ The Kansai Electric Power Co., Inc., 8 Yokota, 13 Goichi Mihama-cho, Mikata-gun, Fukui-ken 919-1141, Japan \\ Correspondence should be addressed to Takeshi Takeda; takeda.takeshi@jaea.go.jp
}

Received 27 January 2016; Accepted 10 May 2016

Academic Editor: Tim Haste

Copyright (C) 2016 Takeshi Takeda et al. This is an open access article distributed under the Creative Commons Attribution License, which permits unrestricted use, distribution, and reproduction in any medium, provided the original work is properly cited.

\begin{abstract}
Two tests related to a new safety system for a pressurized water reactor were performed with the ROSA/LSTF (rig of safety assessment/large scale test facility). The tests simulated cold leg small-break loss-of-coolant accidents with 2-inch diameter break using an early steam generator (SG) secondary-side depressurization with or without release of nitrogen gas dissolved in accumulator (ACC) water. The SG depressurization was initiated by fully opening the depressurization valves in both SGs immediately after a safety injection signal. The pressure difference between the primary and SG secondary sides after the actuation of ACC system was larger in the test with the dissolved gas release than that in the test without the dissolved gas release. No core uncovery and heatup took place because of the ACC coolant injection and two-phase natural circulation. Long-term core cooling was ensured by the actuation of low-pressure injection system. The RELAP5 code predicted most of the overall trends of the major thermal-hydraulic responses after adjusting a break discharge coefficient for two-phase discharge flow under the assumption of releasing all the dissolved gas at the vessel upper plenum.
\end{abstract}

\section{Introduction}

The pressurized water reactor (PWR) electric utilities and vender, and so forth, in Japan [1] are progressing to develop a reliable alternative safety measure to cool the reactor core under a small-break loss-of-coolant accident (SBLOCA) of a PWR using an early steam generator (SG) secondary-side depressurization [2] by means of steam discharge through the SG depressurization valves, as shown in Figure 1. The primary depressurization through the SG depressurization is due to steam condensation in the SG U-tubes. Asaka et al. [3] have reported that the onset timing of the SG depressurization should affect the core cooling by the actuation of accumulator (ACC) system of emergency core cooling system (ECCS) in cold leg SBLOCAs under total failure of high-pressure injection system of ECCS in a PWR. The safety measure of an early SG depressurization promotes an early activation of
ACC system to assure the core cooling even under loss of the high-pressure injection system.

The feasibility of the safety measure has been confirmed by tests using the large scale test facility (LSTF) [4], where full-pressure simulation can be achieved, in the rig of safety assessment (ROSA) program at Japan Atomic Energy Agency since 2011. The LSTF simulates a Westinghousetype four-loop $3423 \mathrm{MW}$ (thermal) PWR by a full-height and $1 / 48$ volumetrically scaled two-loop system. A series of the ROSA/LSTF tests concerning the PWR safety system included the cold leg SBLOCA tests with different break sizes using the early SG depressurization. The authors [5] have shown that core uncovery and heatup took place by core boiloff in the 8-inch diameter break test, and coolant injection from the ACC system was confirmed to be effective in avoiding a significant increase in cladding surface temperature of simulated fuel rods. In contrast, no core uncovery and heatup 


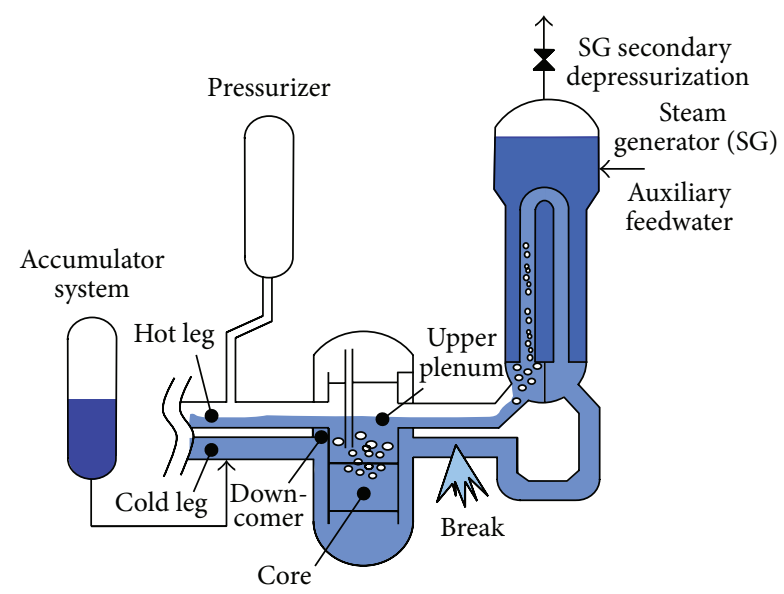

FIgURE 1: Coolant behavior during PWR cold leg SBLOCA with SG secondary-side depressurization.

occurred in the 4-inch diameter break test due to a smaller break flow rate than in the 8 -inch diameter break test.

When noncondensable gas (nitrogen gas) accumulates in the SG U-tubes due to failure of the ACC system isolation after the coolant injection initiation, degradation in the condensation heat transfer affects the core cooling [6]. Meanwhile, some nitrogen gas is dissolved in water in an ACC tank that is pressurized with nitrogen cover gas [7]. However, there have scarcely been experimental and analytical studies on such dissolved noncondensable gas behavior during SBLOCAs in PWRs. Yonomoto et al. $[8,9]$ have presented the notion that the SG U-tube flow behavior and the primary loop flow rate should be dependent on the release of noncondensable gas (air) dissolved in the coolant injected by the actuation of a gravity-driven passive safety injection system during the SBLOCA with the SG depressurization in some future PWR design, based on the simulation tests with the ROSA/LSTF. Some researchers [1012] have investigated the major thermal-hydraulic responses against influences of the dissolved nitrogen gas release from the ACC tank during the SBLOCAs in the existing PWRs, by calculations with best-estimate computer codes. It is thus necessary to clarify how the release of nitrogen gas dissolved in the ACC water affects the PWR SBLOCA progression with the SG depressurization through integral system tests under the well-defined boundary conditions.

In the research on the PWR safety system, two ROSA/ LSTF tests were conducted simulating the cold leg SBLOCAs with or without the release of nitrogen gas dissolved in the ACC water. The common break-size condition of 2-inch diameter break was selected to well observe the behavior of dissolved nitrogen gas during natural circulation (NC). Only in the test with the release of dissolved nitrogen gas, water containing dissolved nitrogen gas was used as coolant in the ACC tank where a concentration of the dissolved nitrogen gas corresponds to the saturated concentration at the cover gas pressure (to be described in Section 3.2). For each of the LSTF tests, the SG depressurization was initiated by fully opening the depressurization valves in both SGs

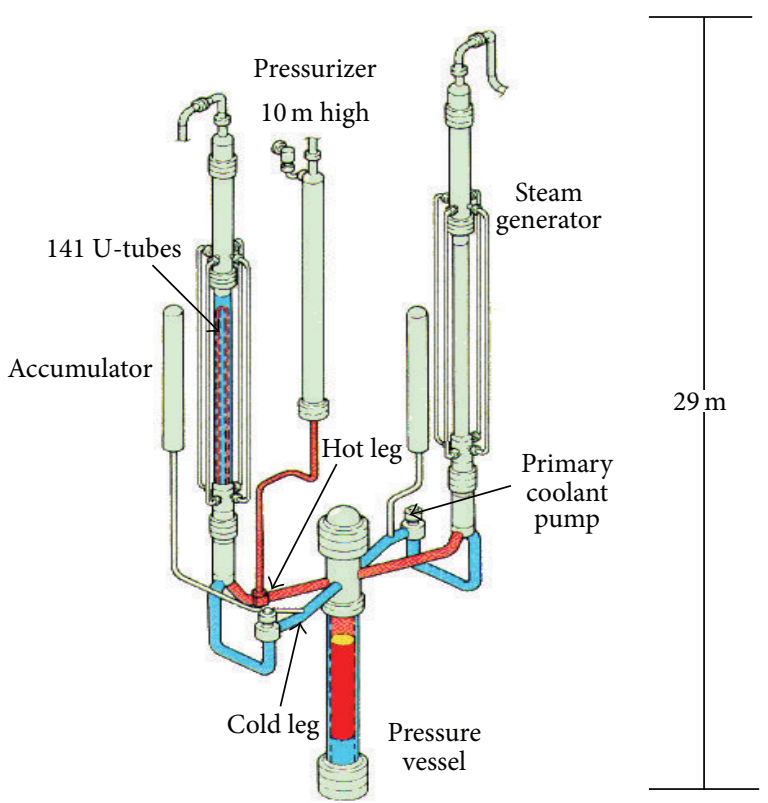

FIgURE 2: Schematic view of ROSA/LSTF.

immediately after a safety injection signal. Flow capacity of the SG depressurization valve at a certain SG secondaryside pressure was almost twice that of a SG relief valve [6], which is available for the SG depressurization in the reference PWR of the LSTF. Auxiliary feedwater was injected into the secondary side of both SGs about 2 min after the safety injection signal. As a conservative assumption to the core cooling, the ACC system injected coolant into a cold leg in the loop with pressurizer only. The low-pressure injection (LPI) system of the ECCS injected coolant into vessel downcomer through direct vessel injection lines [13] in both loops. The two LSTF tests were analyzed by RELAP5/MOD3.2.1.2 code [14] to clarify the remaining subjects. This paper describes major results from the LSTF tests for the PWR safety system and from the RELAP5 posttest analyses.

\section{ROSA/LSTF}

The ROSA/LSTF is the world's largest integral test facility designed to investigate multidimensional thermal-hydraulic responses during PWR transients and accidents. The LSTF simulates a Westinghouse-type four-loop $3423 \mathrm{MW}$ (thermal) PWR by a two-loop system model with full height and $1 / 48$ of the volume. Figure 2 shows the schematic view of the LSTF that is composed of a pressure vessel, pressurizer, and primary loops. Each loop includes an active SG, primary coolant pump, and hot and cold legs. Loops with and without pressurizer are designated as loop-A and loop-B, respectively. Each SG is furnished with 141 full-size U-tubes (innerdiameter of $19.6 \mathrm{~mm}$, nine different lengths as shown in Table 1), inlet and outlet plena, boiler section, steam separator, steam dome, steam dryer, main steam line, four downcomer pipes, and other internals. Six U-tubes are instrumented for each SG. Instrumented U-tubes designated as tubes 1 and 6 are short tubes (type 1 in Table 1), tubes 2 and 5 are medium 
TABLE 1: Details of LSTF U-tubes in each SG.

\begin{tabular}{cccc}
\hline Type & Straight length $(\mathrm{m})$ & Number of tubes & $\begin{array}{c}\text { Instrumented } \\
\text { tubes }\end{array}$ \\
\hline 1 & 9.44 & 21 & $\begin{array}{c}\text { Two short } \\
\text { tubes (tubes 1 } \\
\text { and 6) }\end{array}$ \\
2 & 9.59 & 19 & \\
3 & 9.74 & 19 & \\
4 & 9.89 & 19 & Two medium \\
5 & 10.04 & 17 & $\begin{array}{c}\text { tubes (tubes 2 } \\
\text { and 5) }\end{array}$ \\
6 & 10.19 & 15 & \\
7 & 10.34 & 13 & Two long \\
8 & 10.49 & 11 & \\
9 & 10.64 & 7 & tubes (tubes 3 \\
& & & and 4) \\
\hline
\end{tabular}

tubes (type 5), and tubes 3 and 4 are long tubes (type 9). The hot and cold legs, $207 \mathrm{~mm}$ in inner-diameter, are sized to conserve the volumetric scale $(2 / 48)$ and the ratio of the length to the square root of pipe diameter to better simulate the flow regime transitions in the primary loops [15].

The LSTF core, $3.66 \mathrm{~m}$ in active height, consists of 1008 electrically heated rods in 24 rod bundles to simulate the fuel rod assembly in the PWR. Axial core power profile is a 9step chopped cosine with a peaking factor of 1.495 . The radial power profile is achieved by providing three different (high, mean, and low) power bundles with a maximum peaking factor of 1.51 for high-power bundle. The LSTF initial core power of $10 \mathrm{MW}$ corresponds to $14 \%$ of the volumetrically scaled (1/48) PWR nominal core power because of a limitation in the capacity of power supply. The core power after the test initiation then is kept constant at $10 \mathrm{MW}$ for a little while before the core power starts to follow predetermined power decay curve. All the types of ECCS furnished to the PWR are equipped in the LSTF.

\section{LSTF Test and RELAP5 Code Analysis Conditions}

3.1. Common Conditions of LSTF Tests. The break was simulated by using a sharp-edge orifice, downwardly mounted flush with the cold leg inner surface in loop- $\mathrm{B}$, as shown in Figure 3. The orifice size corresponds to 2-inch diameter break in a PWR as a subject of this study.

The test was initiated by opening a break valve located downstream of the break orifice at time zero. Table 2 shows the major test conditions. Initial steady-state conditions such as pressurizer pressure and fluid temperatures in hot and cold legs were $15.7 \mathrm{MPa}, 600 \mathrm{~K}$, and $563 \mathrm{~K}$, respectively, according to the PWR conditions. The LSTF core power decay curve after a scram signal was predetermined on the basis of some calculations of the PWR by Mitsubishi Heavy Industries, Ltd. The LSTF core power was maintained at the initial value of $10 \mathrm{MW}$ for a short while until the scaled core decay power dropped to $10 \mathrm{MW}$ after the scram signal. The LSTF core

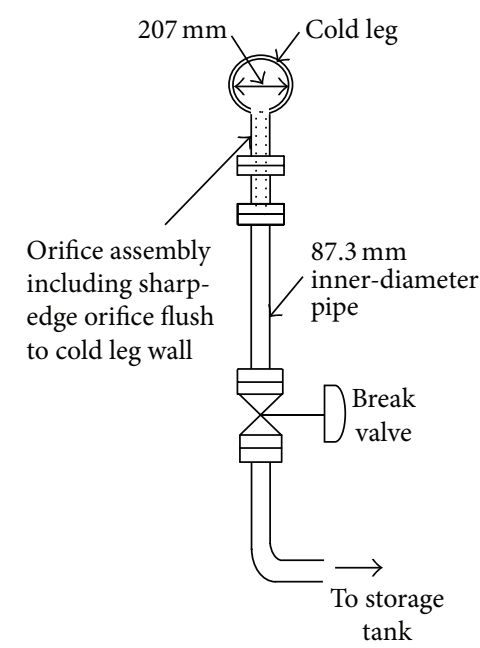

FIGURE 3: Schematic view of LSTF break unit.

TABLE 2: Major test conditions in each LSTF test.

\begin{tabular}{lc}
\hline Item & Condition \\
\hline Initial core power & $10 \mathrm{MW}$ \\
Initial pressurizer pressure & $15.7 \mathrm{MPa}$ \\
Initial hot leg fluid temperature & $600 \mathrm{~K}$ \\
Initial cold leg fluid temperature & $563 \mathrm{~K}$ \\
Initial SG secondary-side pressure & $7.3 \mathrm{MPa}$ \\
Initial SG secondary-side collapsed liquid & About $10 \mathrm{~m}$ \\
level & Pressurizer \\
& pressure $=$ \\
Generation of scram signal & $12.8 \mathrm{MPa}$ \\
& Pressurizer \\
Generation of safety injection signal & pressure $=12.1 \mathrm{MPa}$ \\
Start of SG secondary-side & 10 s after safety \\
depressurization & injection signal \\
& About 2 min after \\
Start of auxiliary feedwater injection & safety injection \\
& signal \\
Actuation of ACC system & Primary pressure $=$ \\
Actuation of LPI system & about $4 \mathrm{MPa}$ \\
& Primary pressure $=$ \\
& $1.0 \mathrm{MPa}$ \\
\hline
\end{tabular}

power started to decay afterwards following the specified core power decay curve. Initial SG secondary-side pressure was raised to $7.3 \mathrm{MPa}$ to limit the primary-to-secondary heat transfer rate to $10 \mathrm{MW}$, while $6.1 \mathrm{MPa}$ is nominal value in the PWR. Initial SG secondary-side collapsed liquid level was set to about $10 \mathrm{~m}$ which corresponds to the medium tube height. The rotation speed of a primary coolant pump in each loop was predetermined considering the characteristics of the PWR pump by Mitsubishi Heavy Industries, Ltd.

Scram and safety injection signals were generated when the pressurizer pressures decreased to 12.8 and $12.1 \mathrm{MPa}$, respectively. Loss of off-site power was assumed to occur concurrently with the scram signal, causing the closure of main steam isolation valves and the termination of main feedwater in both SGs as well as the coastdown of primary 


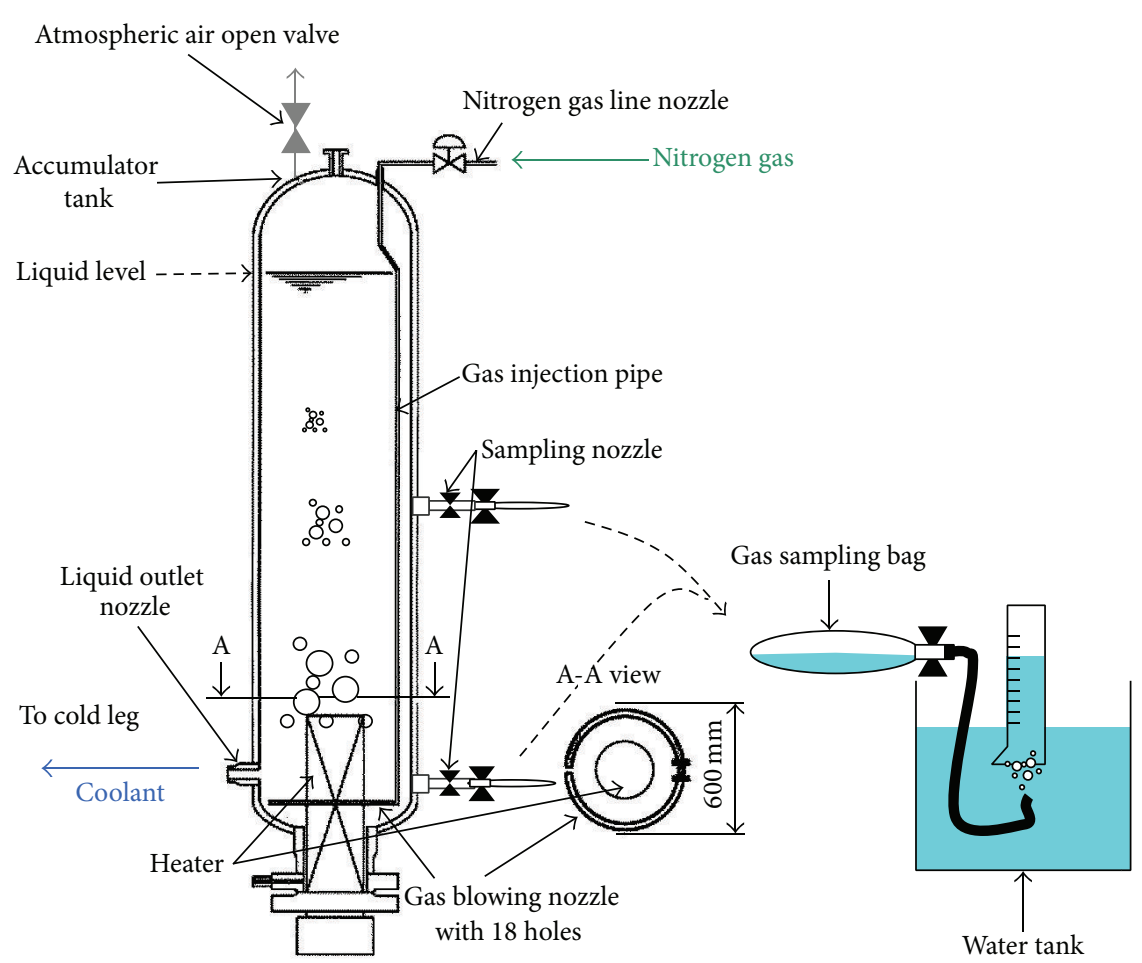

FIGURE 4: Schematic view of LSTF accumulator tank and associated apparatus for measurement of dissolved nitrogen gas concentration.

coolant pumps in both loops. The SG depressurization valve was simulated by using a sharp-edge orifice to provide steam flow rate when SG secondary-side pressure is $8 \mathrm{MPa}$, which corresponds to almost twice that steam flow rate through a SG relief valve in the reference PWR of the LSTF. The SG depressurization was started by fully opening the depressurization valves in both SGs $10 \mathrm{~s}$ after the safety injection signal, taking account of the time of SG main steam isolation valves closure. The auxiliary feedwater was injected into the secondary side of both SGs about $2 \mathrm{~min}$ after the safety injection signal, considering the delay time of the auxiliary feedwater pumps actuation.

The ACC system automatically initiated the injection of coolant at a constant temperature of $322 \mathrm{~K}$ into the cold leg in loop-A only when the primary pressure decreased to about $4 \mathrm{MPa}$. The ACC system was isolated by the closure of an isolation valve on the ACC injection line when liquid level in the ACC tank decreased to a certain low liquid level to simulate the scaled value of the time-integrated injection flow of the PWR. This system isolation prevents the nitrogen cover gas from entering the primary system. The LPI system automatically started coolant injection at a constant temperature of $322 \mathrm{~K}$ into vessel downcomer through direct vessel injection lines in both loops when the primary pressure decreased to 1.0 MPa. The direct vessel injection line was installed between the LPI line end and downcomer nozzle at a certain elevation level below the cold leg.

3.2. Measurement of Dissolved Nitrogen Gas Concentration. Figure 4 shows the schematic view of the ACC tank and associated apparatus for measurement of the dissolved nitrogen gas concentration. A new gas injection pipe, $23 \mathrm{~mm}$ in innerdiameter, was installed in the ACC tank to connect a nitrogen gas line nozzle to a new gas blowing nozzle for nitrogen gas injection. Major procedures to adjust the concentration of the dissolved nitrogen gas in the ACC water are described as follows:

(1) Temperature of water in the ACC tank was increased up to $322 \mathrm{~K}$ by a heater located at the tank bottom, after water level in the tank was fixed at a certain liquid level.

(2) Open an atmospheric air open valve located at the top of the ACC tank.

(3) Nitrogen gas was injected into the ACC tank through the gas blowing nozzle with 18 holes (diameter of $1 \mathrm{~mm}$ each), which surrounded the heater for the ACC tank, to replace nitrogen gas under certain conditions of the gas injection rate and duration.

(4) Close the atmospheric air open valve for the ACC.

(5) During a period until the cover gas pressure increased up to a certain pressure higher than about $4 \mathrm{MPa}$, nitrogen gas was injected into the ACC tank through the gas blowing nozzle to make nitrogen gas dissolve under certain conditions of the gas injection rate and duration.

(6) During a period until the cover gas pressure decreased down to about $4 \mathrm{MPa}$, the concentration of the dissolved nitrogen gas in the ACC water was adjusted to the saturated concentration. 


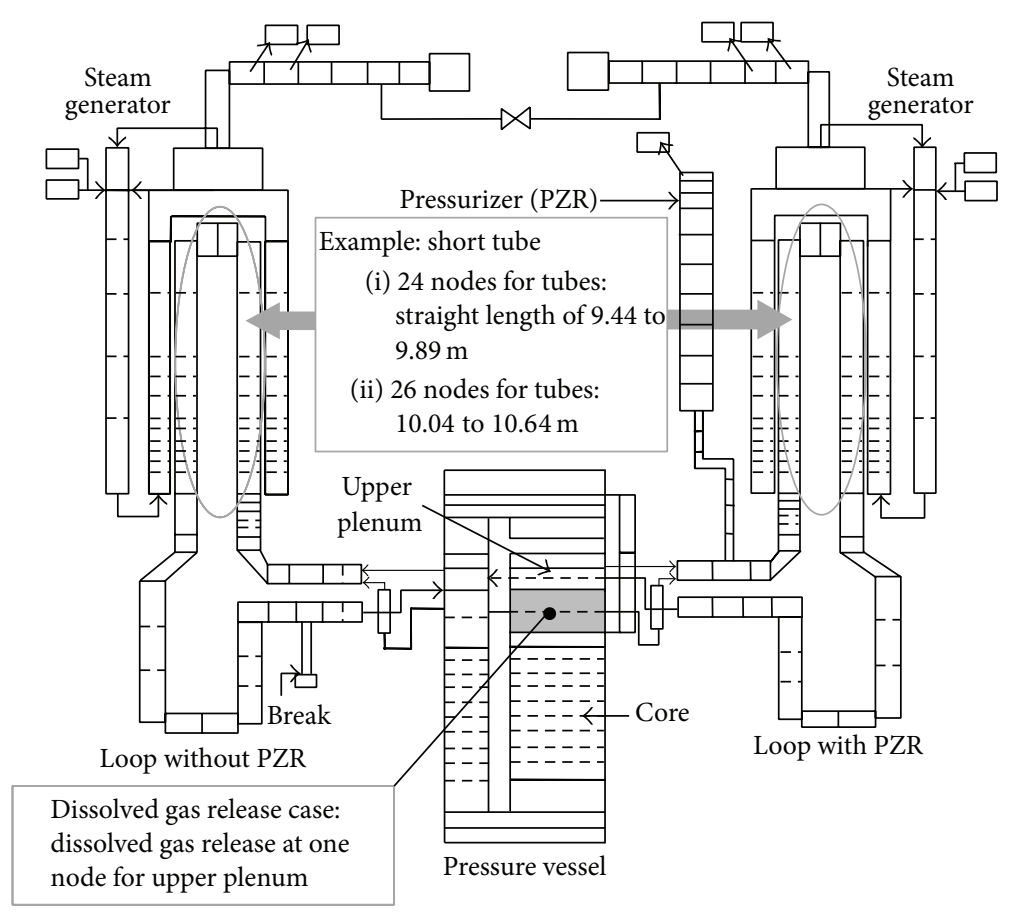

FIgURE 5: Noding schematic of LSTF for RELAP5 analysis.

The initial steady-state conditions shown in Section 3.1 were established after the adjustment of the dissolved nitrogen gas concentration. The procedures for the measurement of the dissolved nitrogen gas concentration are as follows. Water in the ACC tank was collected three times each from two sampling nozzles at different elevations (Figure 4). Water which was collected into a gas sampling bag foams at atmospheric pressure. The sampled gas volume and the sampled water mass then were measured by a measuring cylinder and an electronic scale, respectively. The initial mean concentration $C_{S}\left[\mathrm{Nm}^{3} / \mathrm{kg}\right]$ of the dissolved nitrogen gas was expressed as

$$
C_{S}=\frac{V_{S}}{M_{S}},
$$

where $V_{S}$ is the amount of the sampled gas $\left[\mathrm{Nm}^{3}\right]$ and $M_{S}$ is the sampled water mass $[\mathrm{kg}]$. Here, the nominal condition is defined as a temperature of $273.15 \mathrm{~K}$ and pressure of $0.101325 \mathrm{MPa}$. $C_{S}$ was estimated to be $4.4 \times 10^{-4} \mathrm{Nm}^{3} / \mathrm{kg}$. The saturated concentration $C_{T}\left[\mathrm{Nm}^{3} / \mathrm{kg}\right]$ of the dissolved nitrogen gas was calculated by

$$
C_{T}=P H,
$$

$H$

$$
=\frac{-0.000042264 T^{3}+0.04222 T^{2}-14.138 T+1579.1}{0.101325 \times 10^{-6}},
$$

where $P$ is the cover gas pressure [MPa] and $H$ is Henry's law constant $\left[\mathrm{Nm}^{3} / \mathrm{kg} / \mathrm{MPa}\right]$ [16] depending on the water temperature $T[\mathrm{~K}]$. The initial relative mean concentration $C_{R}$ [\%] of the dissolved nitrogen gas was given by

$$
C_{R}=\frac{C_{S}}{C_{T}} \times 100 .
$$

$C_{R}$ was evaluated to be $97 \%$, indicating that the initial concentration of nitrogen gas dissolved in the ACC water was almost the saturated concentration.

3.3. RELAP5 Calculation Conditions. For each of the LSTF tests, the break was simulated with a sharp-edge orifice. The posttest analysis was performed using the RELAP5 code with a two-phase critical flow model, which has been proposed by Asaka et al. [17], to well predict the discharge rate through the sharp-edge orifice. The model employs the Bernoulli incompressible orifice flow equation with a break discharge coefficient $\left(C_{d}\right)$ of 0.61 for single-phase discharge liquid [18] and the maximum bounding flow theory for two-phase discharge flow [19]. This flow theory assumes that no phase change occurs at all along the flow and that the local slip ratio is equal to $\left(\rho_{\text {liquid }} / \rho_{\text {gas }}\right)^{1 / 3}$, where $\rho$ is the fluid density. $C_{d}$ of 0.84 was used for single-phase discharge steam [20]. Asaka et al. [17] have revealed the notion that the two-phase break flow rate was somewhat overpredicted by this maximum bounding flow model with $C_{d}$ of 0.61 , while the single-phase break flow rate was well predicted by the above manner, through the posttest analysis of a LSTF test with a sharpedge orifice to simulate the break. To better predict the major thermal-hydraulic response, adjustment of $C_{d}$ for two-phase discharge flow was tried through some calculations for each of the LSTF tests (to be mentioned in Sections 4.1.2 and 4.2.2).

Figure 5 shows a noding schematic of LSTF for RELAP5 analysis. The LSTF system is modeled in one-dimensional 
manner including a pressure vessel, primary loops, pressurizer, SGs, and SG secondary-side system. The SG U-tubes were modeled by nine parallel flow channels that correspond to nine different lengths of U-tubes, namely, 24 nodes for short-to-medium tubes (straight length of 9.44 to $9.89 \mathrm{~m}$, four cases in Table 1) and 26 nodes for medium-to-long tubes (straight length of 10.04 to $10.64 \mathrm{~m}$, five cases), for better prediction of the nonuniform coolant behaviors during NC $[21,22]$ (as will be described in Sections 4.1.1 and 4.2.1). The core was represented by nine equal-height volumes that are vertically stacked according to 9-step chopped cosine power profile along the core length. The radial power distribution then was given considering the peaking factor and the number of high-, mean-, and low-power rod bundles. Other initial and boundary conditions were determined according to the LSTF test data.

In the posttest analysis for the test with the release of dissolved nitrogen gas, it was assumed that all the nitrogen gas dissolved in the ACC water would be released at the vessel upper plenum due to the fluid boiling at the core. All the dissolved nitrogen gas, therefore, was released at one of the nodes for the vessel upper plenum, as shown in Figure 5. In addition, the dissolved nitrogen gas release was started simultaneously with the ACC coolant injection initiation. Certain values of the dissolved nitrogen gas release flow rate versus the ACC flow rate were given further, based on the estimation using the cover gas pressure and Henry's law constant as a function of the water temperature in (2) mentioned above.

\section{LSTF Test and RELAP5 Code Analysis Results}

\subsection{Test with Release of Dissolved Nitrogen Gas}

4.1.1. Major Phenomena Observed in the Test. Table 3 summarizes the chronology of major events in the test with the release of dissolved nitrogen gas. Figures 6-16 show the test results. The time-integrated break flow is evaluated from the liquid level increase in the break flow storage tank. Break flow changed from single-phase liquid to two-phase flow soon after liquid level formed at the cold leg, causing a decrease in the break flow rate (Figures 6 and 7). The primary pressure started to decrease after the break, while the SG secondary-side pressure increased up to $8.2 \mathrm{MPa}$ until the onset of the SG depressurization after the closure of main steam isolation valves in both SGs following the scram signal (Figure 9(a)). The primary pressure became close to the SG secondary-side pressure by the time the ACC system was actuated because of the SG depressurization (Figure 8). There was some difference between the primary and SG secondary pressures due to the release of nitrogen gas dissolved in the ACC water (Figure 9(b)), unlike the test without the release of dissolved nitrogen gas (to be shown in Figure 21(b)). This latter test result was also different from the results of previous LSTF tests on SBLOCAs with the nitrogen cover gas inflow, which indicated that large pressure difference appeared between the primary and SG secondary sides after the completion of ACC coolant injection [6]. The
TABLE 3: Chronology of major events in LSTF tests with or without release of dissolved nitrogen gas.

\begin{tabular}{lcc}
\hline Event & \multicolumn{2}{c}{ Time (s) } \\
& $\begin{array}{c}\text { Release of } \\
\text { dissolved } \\
\text { nitrogen gas }\end{array}$ & $\begin{array}{c}\text { No release of } \\
\text { dissolved } \\
\text { nitrogen gas }\end{array}$ \\
\hline $\begin{array}{l}\text { Break valve open } \\
\text { Generation of scram signal }\end{array}$ & 120 & 0 \\
$\begin{array}{l}\text { Generation of safety injection } \\
\text { signal }\end{array}$ & 148 & 118 \\
Start of primary coolant pumps & 158 & 149 \\
coastdown & & \\
$\begin{array}{l}\text { Start of SG secondary-side } \\
\text { depressurization }\end{array}$ & 159 & 165 \\
Start of auxiliary feedwater & 285 & \\
injection & 365 & 365 \\
Liquid level formation at cold leg & 409 & 407 \\
Stop of primary coolant pumps & 768 & 761 \\
Actuation of ACC system & 3162 & 2749 \\
Isolation of ACC system & 3651 & 2632 \\
Actuation of LPI system & 4237 & 3225 \\
Core power off & 4250 & 3234 \\
Break valve closure & & \\
\hline
\end{tabular}

SG secondary-side collapsed liquid level greatly decreased after the onset of the SG depressurization and gradually recovered by the auxiliary feedwater injection into the $S G$ secondary side (Figure 10). Regarding the SG U-tubes in loop-A, the collapsed liquid levels began to drop at $400 \mathrm{~s}$ in both long tubes (tubes 3 and 4) and short tubes (tubes 1 and 6) but at 800-850 s in medium tubes (tubes 2 and 5), as shown in Figure 11. The water column changed in the SG U-tubes in nonuniform manner under NC with the dissolved nitrogen gas. Such nonuniform flow also occurred among the SG Utubes in previous steady-state NC tests with the LSTF under certain low core power conditions [23].

The primary coolant pumps were stopped by $409 \mathrm{~s}$, according to the predetermined pump rotation speed, which affected the primary loop flow rate (Figure 12). NC was established in both primary loops thereafter. Two-phase NC has continued even under the dissolved nitrogen gas release because of liquid level formation at the hot leg and no complete draining of coolant in the SG U-tubes (Figures 11-13). The primary loop flow rate after the ACC actuation, however, was smaller than that in the test without the release of dissolved nitrogen gas (to be shown in Figure 23). No core uncovery and heatup took place because of the ACC coolant injection and two-phase NC (Figures 14 and 15). The liquid levels at the cold and hot legs recovered by the ACC or LPI actuation (Figures 7, 8, and 13). Significant oscillation appeared in the ACC flow rate until the ACC system isolation after around $2250 \mathrm{~s}$ because large fluctuation occurred in the cold leg pressure probably due to influences of the dissolved nitrogen gas release (Figure 8), unlike the test without the release of dissolved nitrogen gas (to be shown in Figure 20).

Figure 16 shows the measured fluid temperatures near the top of instrumented SG U-tubes shown in Table 1 in loop-A, taking account of the gas phase in the SG U-tubes (Figure 11). 


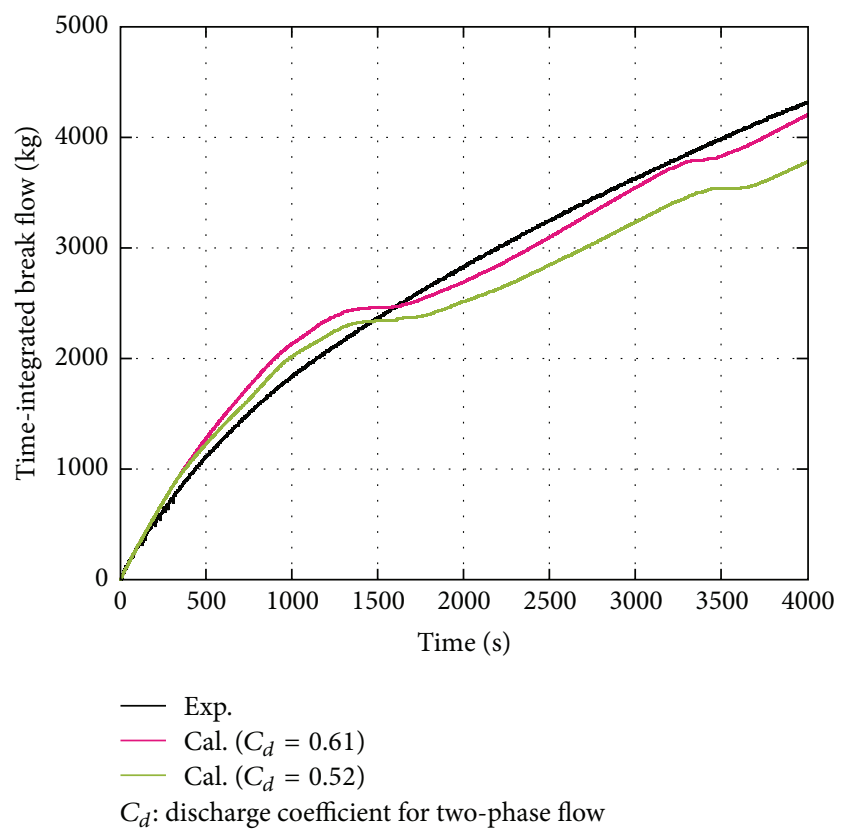

FIGURE 6: LSTF and RELAP5 results for time-integrated break flow in case of release of dissolved gas.

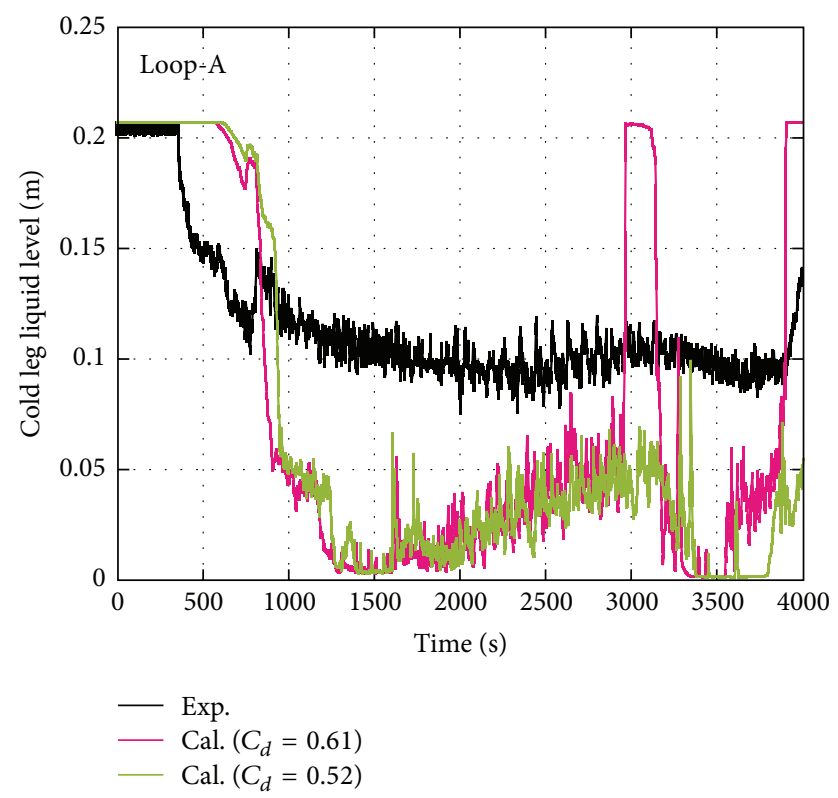

FIGURE 7: LSTF and RELAP5 results for cold leg liquid level in loopA in case of release of dissolved gas.

The fluid temperatures were compared with the saturated temperature based on the vessel upper plenum pressure as reference. The local gas phase temperatures near the top of the instrumented U-tubes became below the saturated temperature after around $1500 \mathrm{~s}$ following the ACC actuation. In most of the instrumented U-tubes, the degree of the subcooling increased with time. These suggest the presence of the dissolved nitrogen gas in the SG U-tubes.

The primary and SG secondary-side pressures decreased to 0.9 and $0.6 \mathrm{MPa}$, respectively, with well-cooled core at
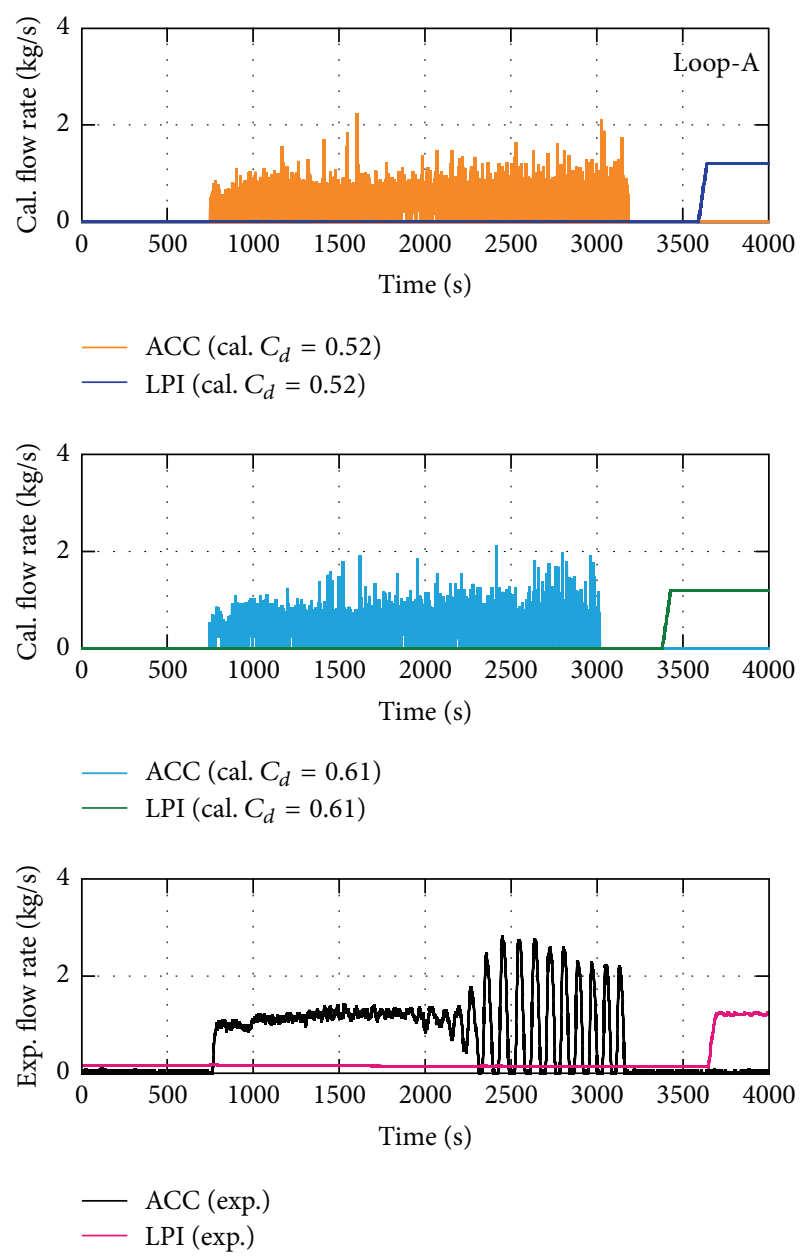

FIGURE 8: LSTF and RELAP5 results for flow rates of ACC and LPI systems in loop-A in case of release of dissolved gas.

$4000 \mathrm{~s}$ after the LPI actuation (Figures 8 and 9(b)). The total nitrogen gas volume in the U-tubes of both SGs at the test end (break valve closure) was evaluated using the total pressure, which was represented by the SG U-tube pressure estimated from the measured data, and the steam saturation pressure on the basis of the steam temperatures measured at the SG Utubes by assuming $100 \%$ relative humidity of saturated steam in steam-gas mixture. The total nitrogen gas volume in the Utubes of both SGs was estimated to be $0.90 \mathrm{Nm}^{3}$. The mean value of the nitrogen gas volume to the steam-gas mixture volume in the SG U-tube would be about $28 \%$, if all the dissolved nitrogen gas was distributed uniformly among the SG U-tubes under the pressure and temperature conditions at the test end.

4.1.2. Comparison of Calculated Results with Test Data. The RELAP5 code well predicted the break flow rate during single-phase liquid discharge period when a $C_{d}$ value for single-phase discharge liquid is 0.61 , though with a tendency that liquid level formed at the cold leg later in the analysis compared to that in the LSTF test (Figures 6 and 7). For a $C_{d}$ value of 0.61 for two-phase discharge flow, the time-integrated 

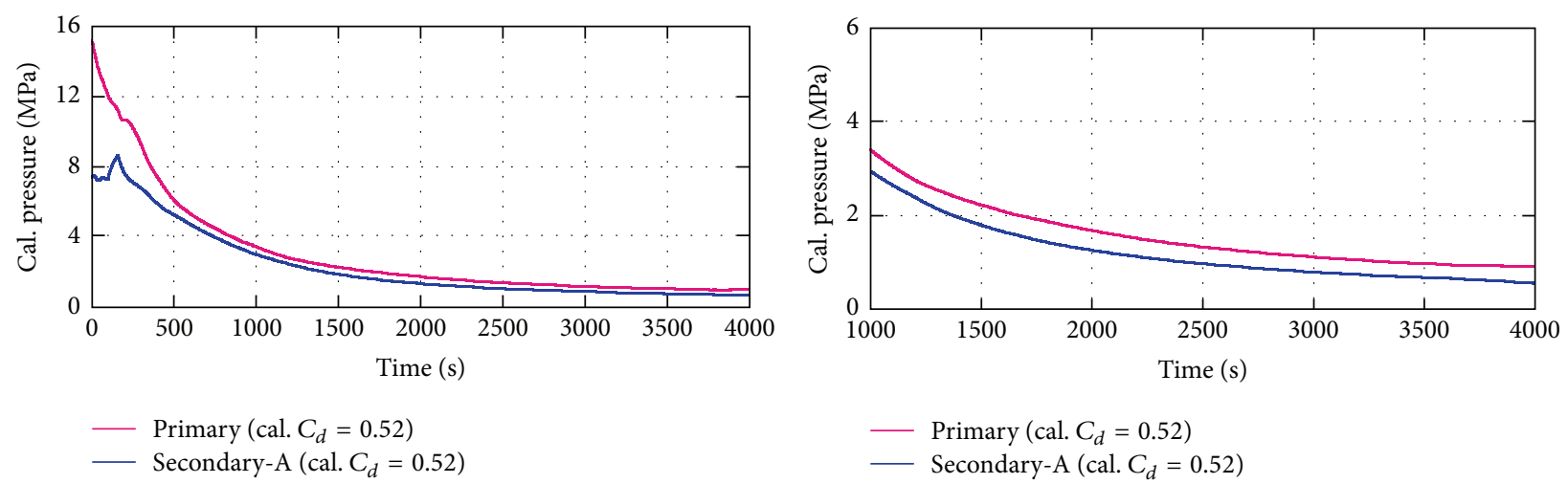

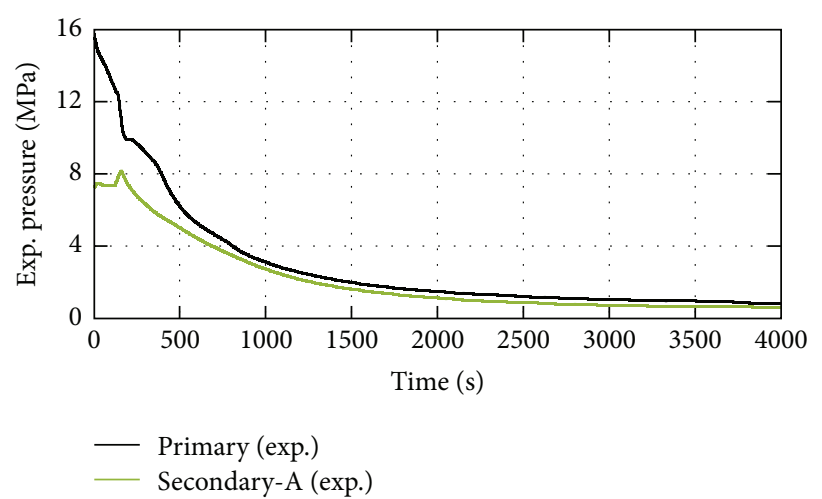

(a) Overall transient $(0-4000 \mathrm{~s})$

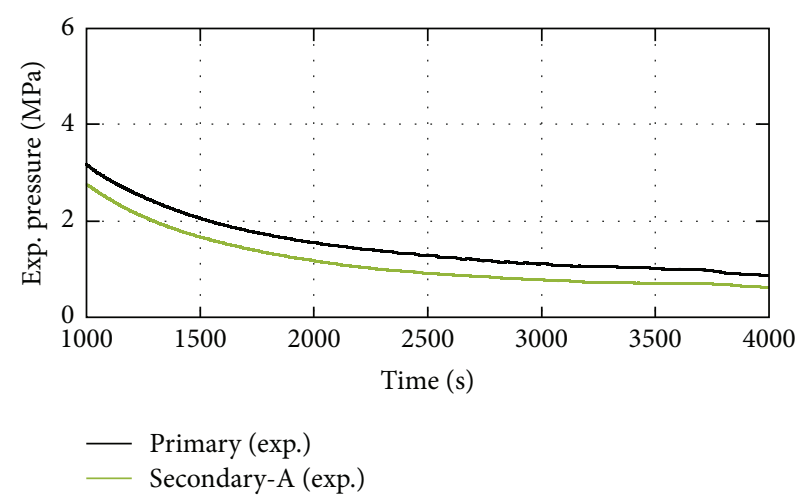

(b) Local transient (1000-4000s)

FIGURE 9: LSTF and RELAP5 results for primary and SG secondary pressures in loop-A in case of release of dissolved gas.

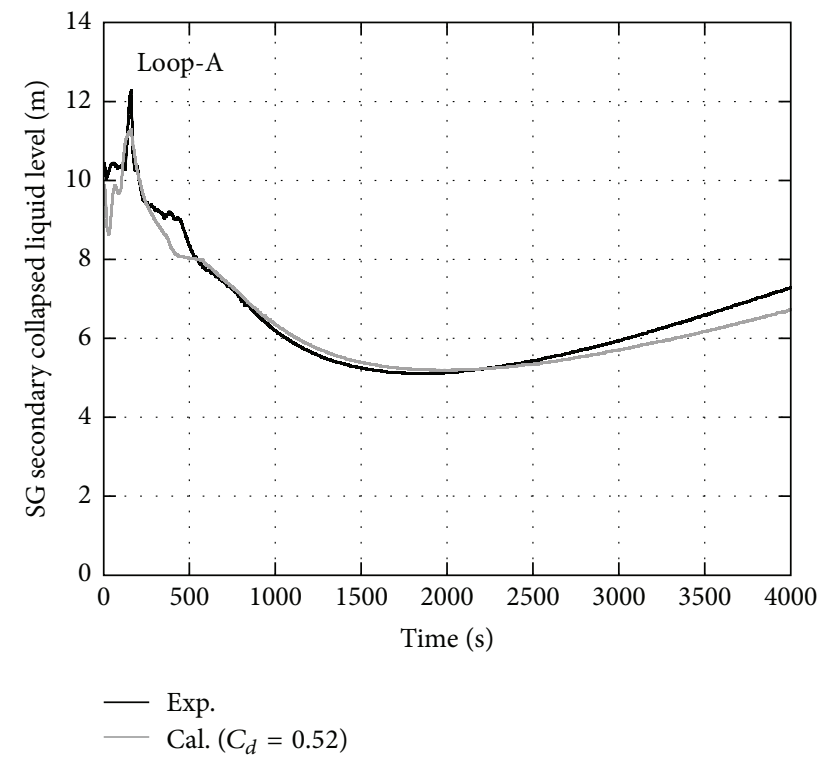

FIGURE 10: LSTF and RELAP5 results for SG secondary-side collapsed liquid level in loop-A in case of release of dissolved gas.

break flow was overpredicted until around $1600 \mathrm{~s}$ while it was underpredicted thereafter (Figure 6). In the analysis, the cold leg became full of liquid again after the ACC actuation at around $3000 \mathrm{~s}$, unlike the LSTF test (Figure 7). The timings of the ACC completion and the LPI actuation were earlier in the analysis compared to the LSTF test (Figure 8). When $C_{d}$ for two-phase discharge flow was adjusted to be 0.52 , the timeintegrated break flow was better predicted until around $1500 \mathrm{~s}$ while it was underpredicted thereafter. The code reproduced the experimental observation that the cold leg was not full of liquid after the ACC actuation. The timings of the ACC completion and the LPI actuation were in reasonably good agreement with the LSTF test. The code predicted most of the overall trends of the major thermal-hydraulic responses by using $C_{d}$ of 0.52 , as shown in Figures $9-15$. The pressure and collapsed liquid level at the SG secondary side agreed reasonably well with the LSTF test probably due to relatively good prediction of steam discharge rate through the SG depressurization valves (Figures 9 and 10).

There were the following differences between the LSTF test and posttest analysis results for the collapsed liquid levels in the SG U-tubes in loop-A (Figure 11). In the LSTF test, the liquid levels in the SG short tubes gradually recovered and those in other instrumented tubes quickly recovered after the ACC actuation. In the analysis, on the other hand, the liquid levels in all the modeled tubes gradually decreased after the ACC actuation. This may indicate a difficulty in the prediction of the coexistence of two-phase concurrent flow, contributing to heat transfer from the primary to SG secondary sides, and stagnant two-phase stratified flow. Significant oscillation in the ACC flow rate was not properly calculated probably due to failure of prediction of large 

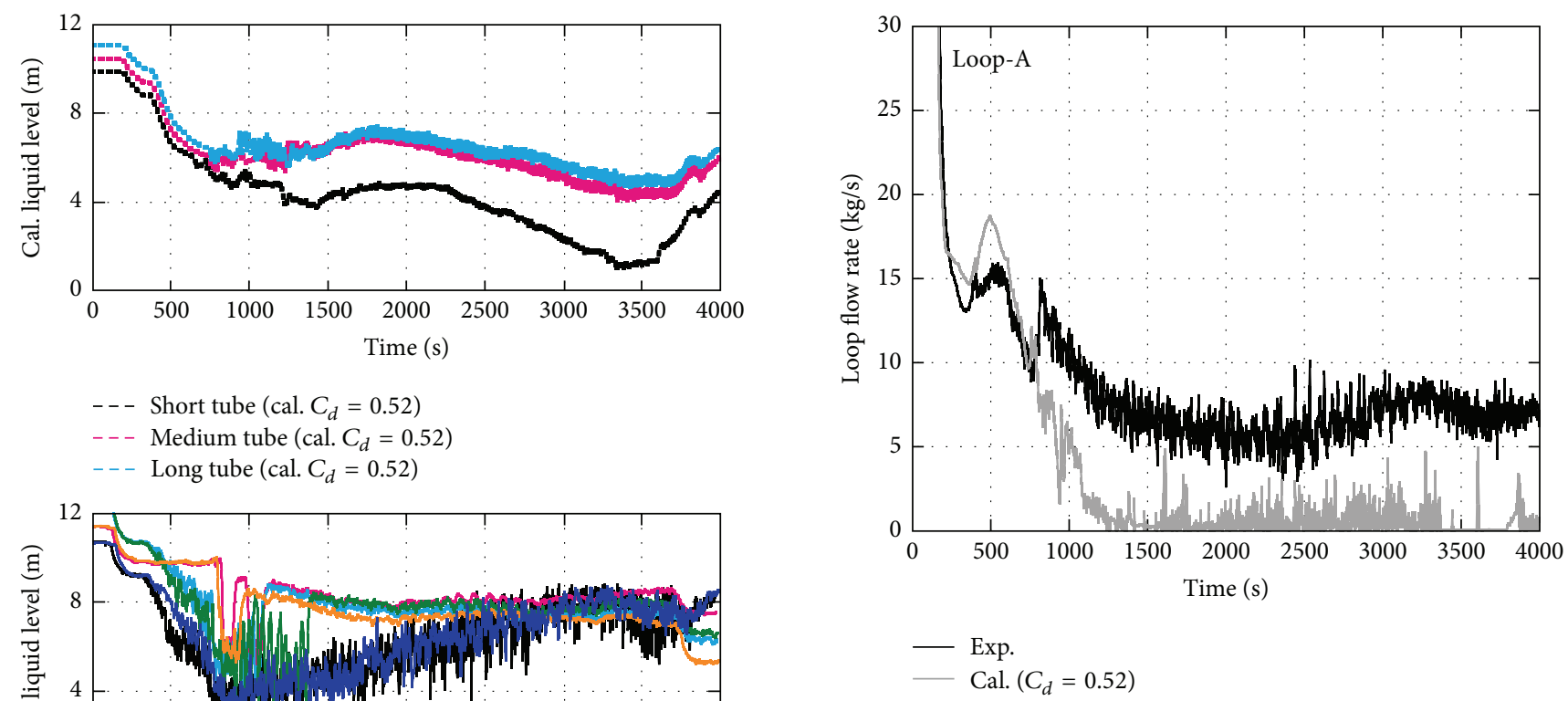

FIGURE 12: LSTF and RELAP5 results for primary loop flow rate in loop-A in case of release of dissolved gas.

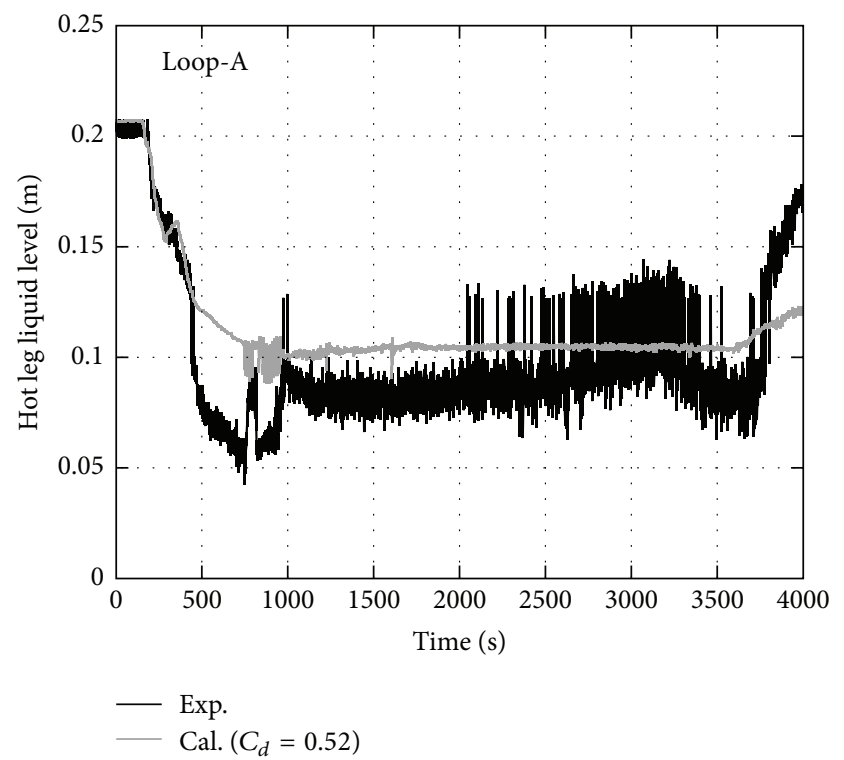

FIGURE 13: LSTF and RELAP5 results for hot leg liquid level in loop$\mathrm{A}$ in case of release of dissolved gas. maximum value between the estimations based on the Shah model for turbulent flow [24] and on the Nusselt model for laminar flow [25] with the multipliers of the VierowSchrock correlation [26]. The multipliers concern the heat transfer degradation expressed as a function of gas mass fraction, which includes effects of the interfacial shear and the gas presence in a vertical tube at low pressures. The code reasonably well predicted the pressure difference between the primary and SG secondary sides under the dissolved nitrogen gas release following the ACC actuation (Figures 8 and $9(\mathrm{~b})$ ). The calculated result confirmed that the simulation methods for the dissolved nitrogen gas release, as mentioned in Section 3.3, were applicable to the posttest analysis.

Calculated gas mass fractions along the length of the modeled U-tube of SG are compared to each other to

clarify the accumulation and distribution of the dissolved nitrogen gas, considering the SG U-tube collapsed liquid level (Figure 11). Figure 17 shows the calculated gas mass fractions at the top, intermediate positions between the top and the middle of short, medium, and long tubes of SG in loop-A. In the intermediate position between the top and the middle of downflow side of the SG tubes, the gas mass fractions began to increase at around $850 \mathrm{~s}$ after the ACC actuation. Trends of the gas mass fractions were similar among the SG tubes. The gas mass fractions became around 0.4 at 4000 s, suggesting that the dissolved nitrogen gas accumulated in the SG Utubes. 


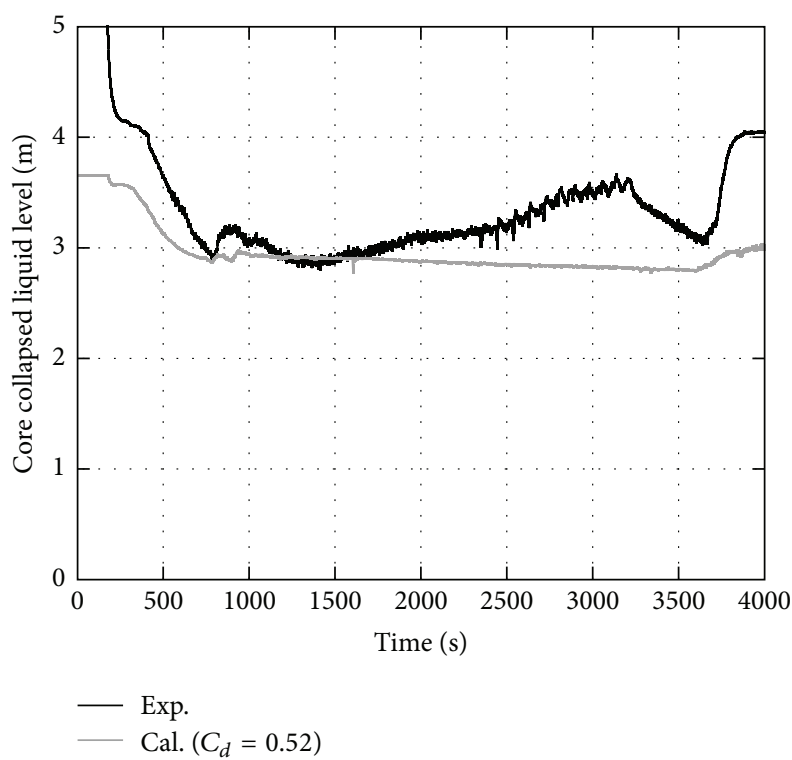

FIGURE 14: LSTF and RELAP5 results for core collapsed liquid level in case of release of dissolved gas.

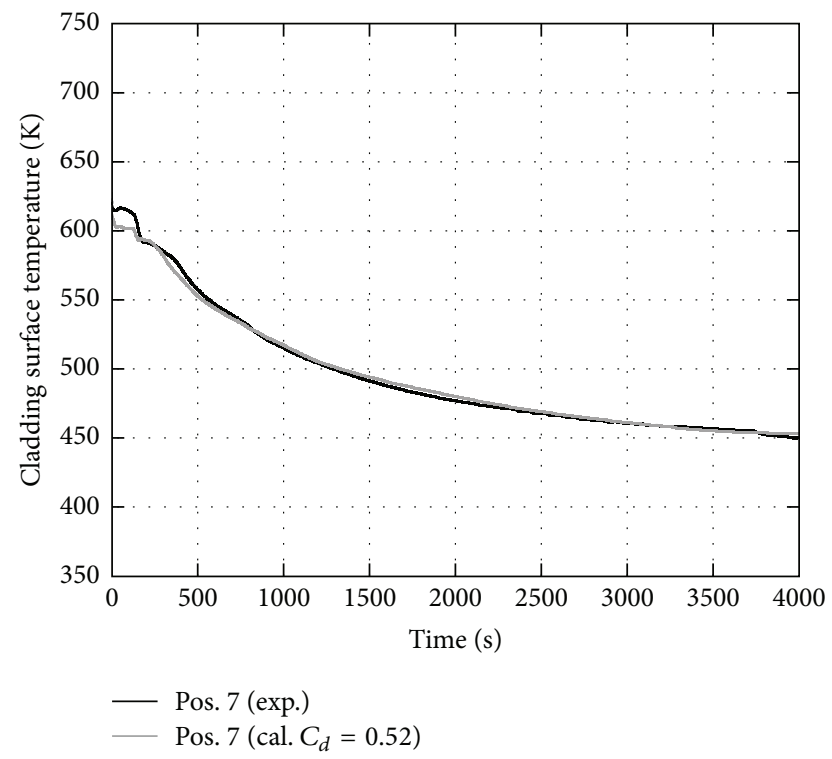

FIGURE 15: LSTF and RELAP5 results for cladding surface temperature in case of release of dissolved gas.

\subsection{Test without Release of Dissolved Nitrogen Gas}

4.2.1. Major Phenomena Observed in the Test. The chronology of major events in the test without the release of dissolved nitrogen gas is summarized in Table 3. The test results are shown in Figures 18-23. The time-integrated break flow depending on the cold leg liquid level was almost the same as that in the test with the release of dissolved nitrogen gas (Figures 18 and 19). The pressure difference between the primary and SG secondary sides after the ACC actuation was smaller than that in the test with the release of dissolved nitrogen gas (Figures 20 and 21(b)). The LPI actuation thus

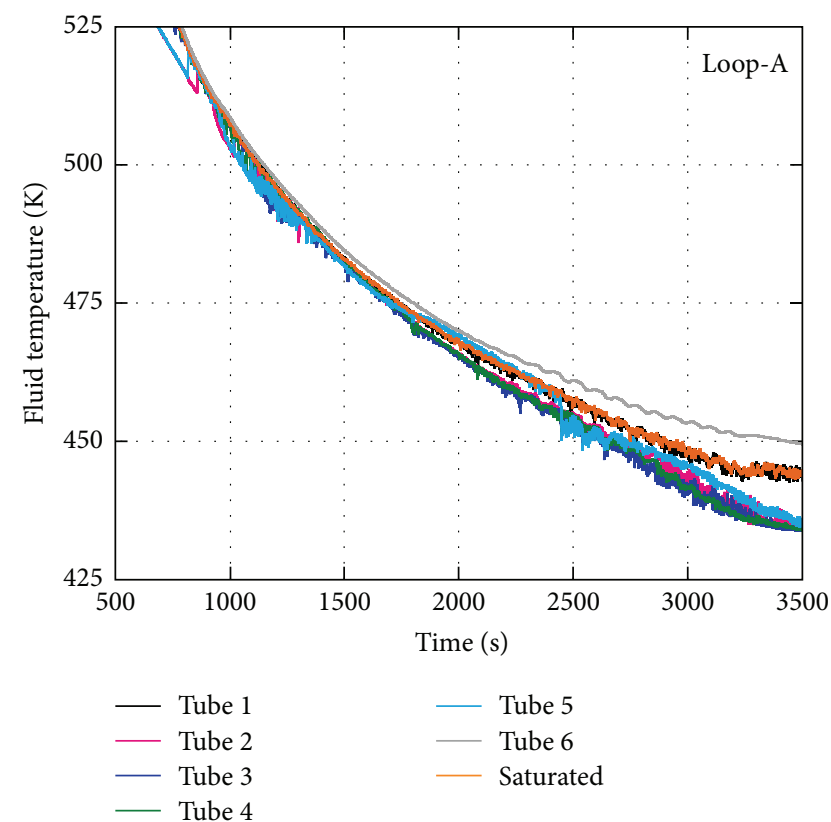

FIGURE 16: Measured fluid temperatures near top of SG U-tubes in loop-A in case of release of dissolved gas.

was earlier than that in the test with the release of dissolved nitrogen gas (Figure 20). The LPI actuation was also a little earlier than the ACC completion, unlike the test with the release of dissolved nitrogen gas. At the final stages of ACC coolant injection, the ACC flow rate increased greatly over a small time span due to the primary pressure decrease by the LPI actuation. As for the SG U-tubes in loop-A, the collapsed liquid levels began to drop at $400 \mathrm{~s}$ in both long and short tubes but at $800 \mathrm{~s}$ in medium tubes (Figure 22). Nonuniform flow behaviors thus were observed in the SG U-tubes during NC. The timings of large level recovery in both medium and long tubes of the SG by the ACC coolant injection, however, were different from those in the test with the release of dissolved nitrogen gas. Continuous two-phase NC led to no core uncovery and heatup, similar to the test with the release of dissolved nitrogen gas (Figure 23). The primary loop flow rate after the ACC actuation was larger than that in the test with the release of dissolved nitrogen gas due to larger ACC flow rate because of lower pressure at the cold leg (Figures 21 and 23). The primary and SG secondary-side pressures decreased to 0.9 and $0.8 \mathrm{MPa}$, respectively, resulting in the LPI actuation and a well-cooled core at $2800 \mathrm{~s}$ (Figures 20 and 21(b)).

4.2.2. Comparison of Calculated Results with Test Data. For a $C_{d}$ value of 0.61 for two-phase discharge flow, the timeintegrated break flow was overpredicted during two-phase flow discharge period (Figure 18). In the analysis, the cold leg became full of liquid again after the ACC actuation, unlike the LSTF test (Figure 19). The timings of the LPI actuation and the ACC completion were earlier in the analysis than those in the LSTF test (Figure 20). By adjusting $C_{d}$ to be 0.45 , the timings of the LPI actuation and the ACC completion as well as the break flow rate were in reasonably good agreement with 


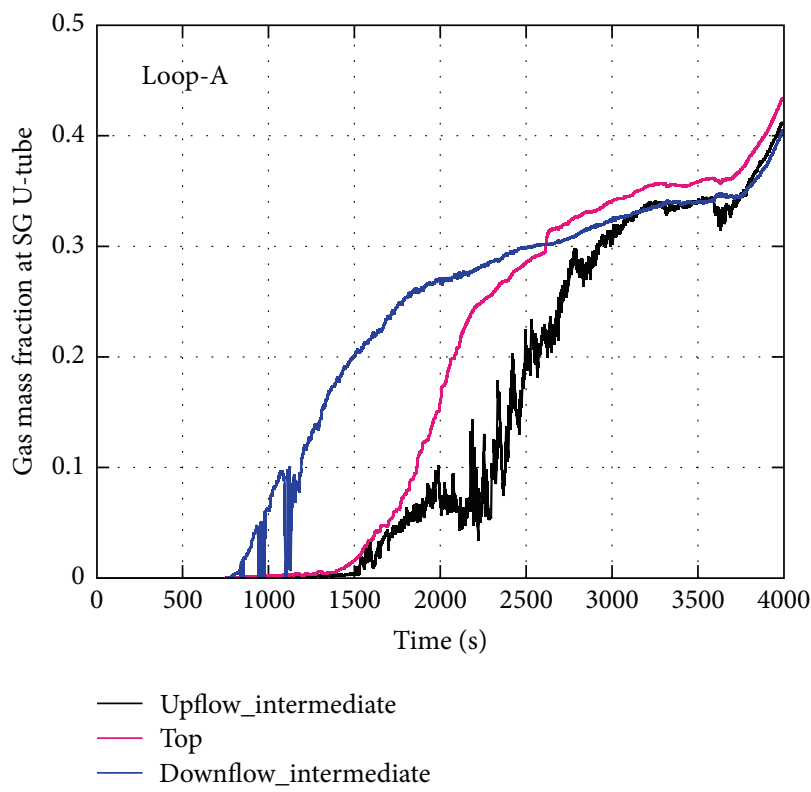

(a) Short tube

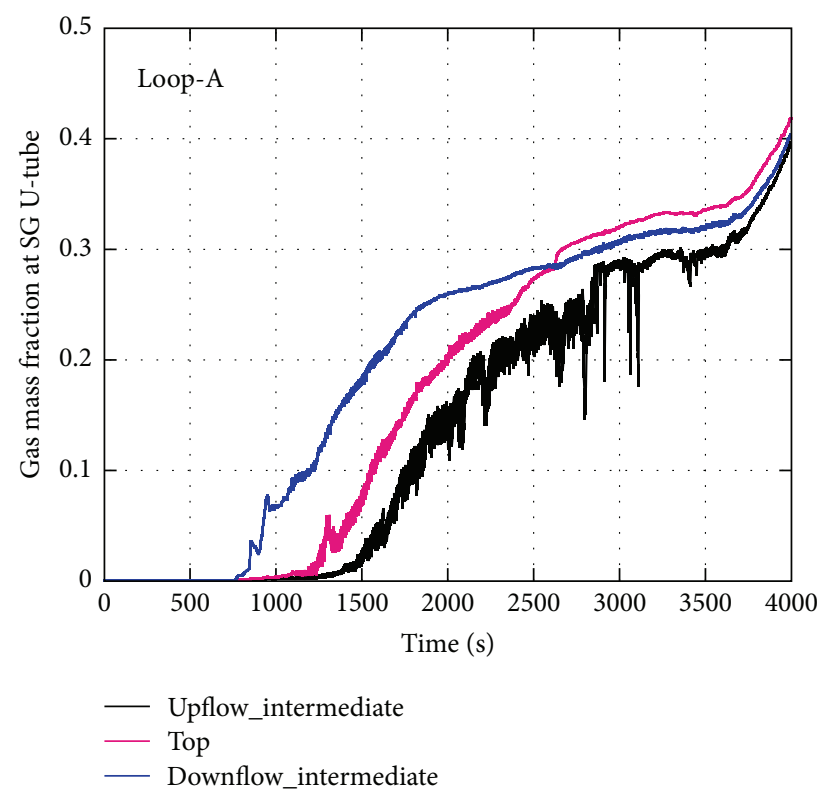

(b) Medium tube

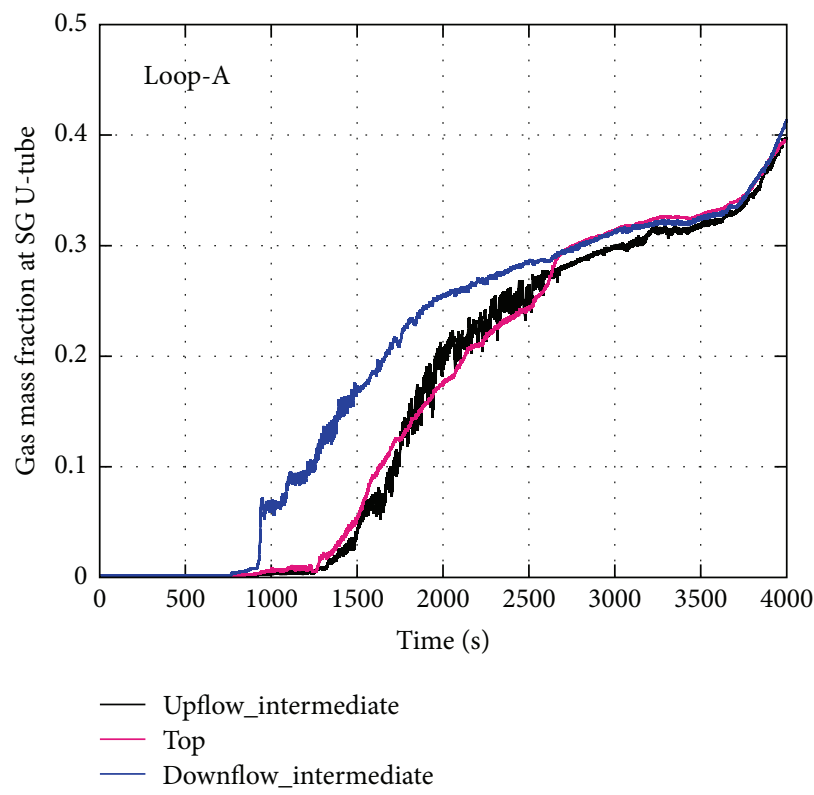

(c) Long tube

FIgURE 17: Calculated gas mass fractions at SG U-tubes in loop-A in case of release of dissolved gas.

those in the LSTF test. The code reproduced the experimental observation that the cold leg was not full of liquid after the ACC actuation. Most of the overall trends of the major thermal-hydraulic responses were predicted by using $C_{d}$ of 0.45, as shown in Figures 21-23.

The code well predicted that the primary pressure became slightly higher than the SG secondary-side pressure after the ACC actuation (Figures 20 and 21(b)). The following discrepancies appeared between the LSTF test and posttest analysis results for the collapsed liquid levels in the SG Utubes in loop-A (Figure 22). In the LSTF test, there were gradual level recovery in the SG short tubes and sudden level recovery in other instrumented tubes after the ACC actuation. In the analysis, on the other hand, no significant level change occurred in any of the modeled tubes after the ACC actuation. Insufficient prediction of nonuniform flow among the SG U-tubes during the NC was similar to the posttest analysis for the test with the release of dissolved nitrogen gas. In the analysis only, large fluctuations appeared in the ACC flow rate (Figure 20). The code underpredicted the cold leg liquid level and the primary loop flow rate during the ACC coolant injection period (Figures 19, 20, and 23). 


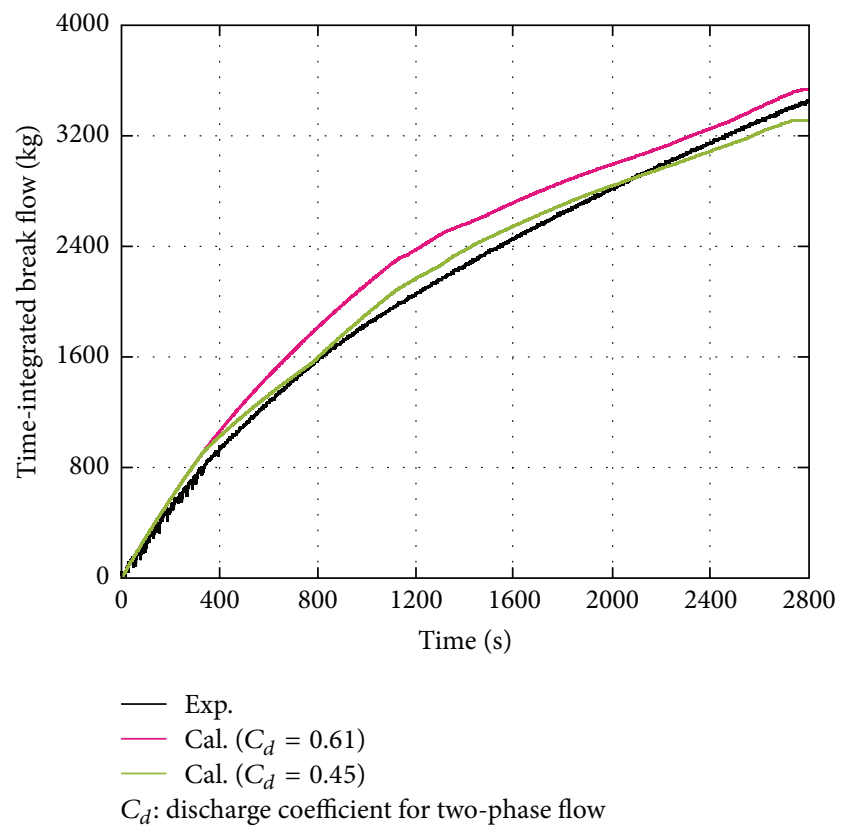

FIGURE 18: LSTF and RELAP5 results for time-integrated break flow in case of no release of dissolved gas.

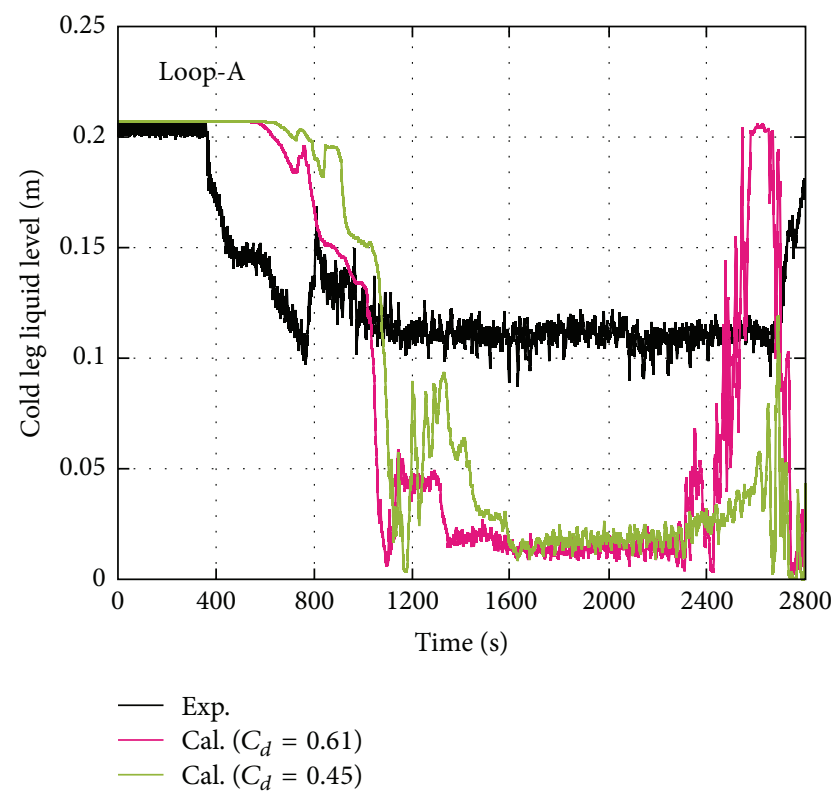

FIGURE 19: LSTF and RELAP5 results for cold leg liquid level in loopA in case of no release of dissolved gas.

\section{Conclusions}

Two ROSA/LSTF tests related to the new safety system for a PWR were conducted simulating cold leg SBLOCAs with 2 -inch diameter break using an early SG secondaryside depressurization with or without the release of nitrogen gas dissolved in ACC water. The SG depressurization was initiated by fully opening the depressurization valves in both SGs immediately after a safety injection signal. Flow capacity
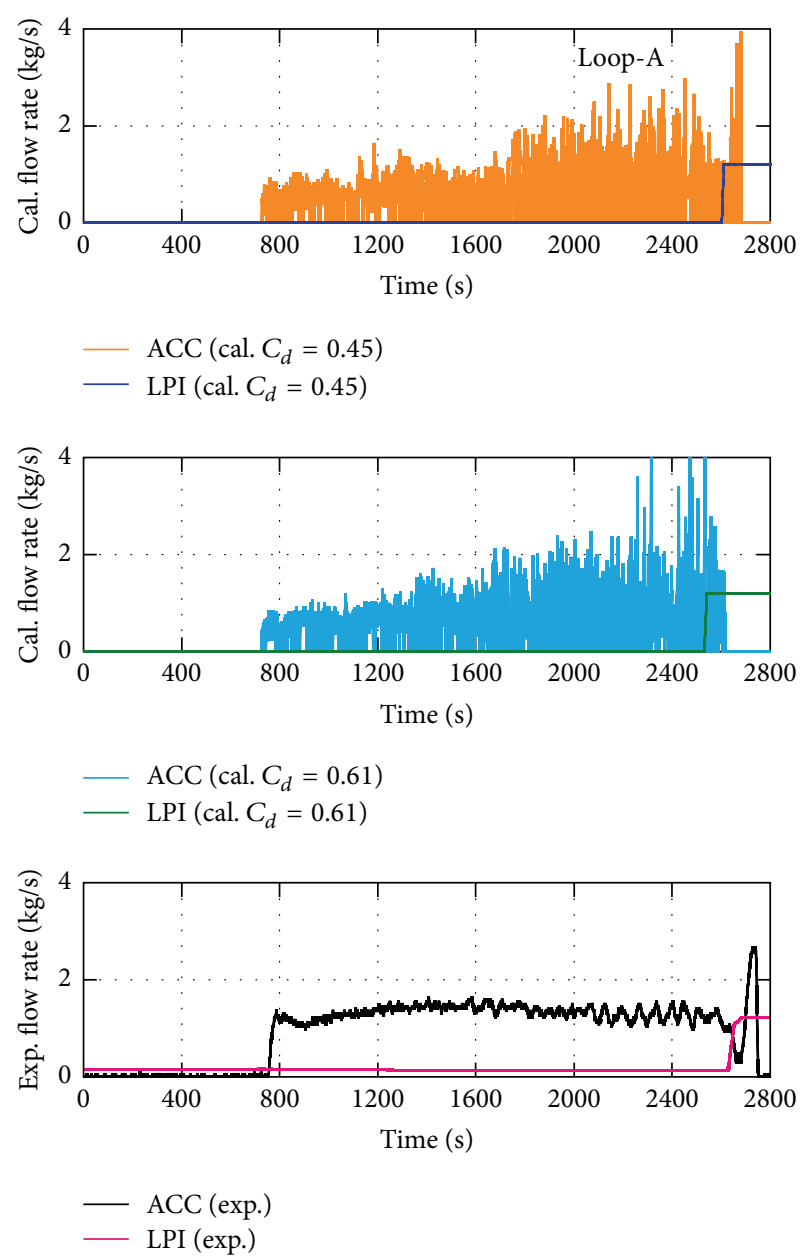

FIGURE 20: LSTF and RELAP5 results for flow rates of ACC and LPI systems in loop-A in case of no release of dissolved gas.

of the SG depressurization valve at a certain SG secondaryside pressure was almost twice that of a SG relief valve in the reference PWR of the LSTF. Auxiliary feedwater was injected into the secondary side of both SGs about $2 \mathrm{~min}$ after the safety injection signal. The results of the LSTF tests were compared with those of the RELAP5 posttest analysis to clarify the remaining subjects. Major results are summarized as follows:

(1) The difference between the primary and SG secondary pressures after the actuation of ACC system was larger in the test with the dissolved gas release than that in the test without the dissolved gas release. Nonuniform flow occurred among the SG U-tubes during NC. Two-phase NC has continued even under the dissolved gas release because of liquid level formation at the hot leg and no complete draining of coolant in the SG U-tubes. The primary loop flow rate after the ACC actuation, however, was smaller in the test with the dissolved gas release than that in the test without the dissolved gas release. There were no core uncovery and heatup because of the ACC coolant 

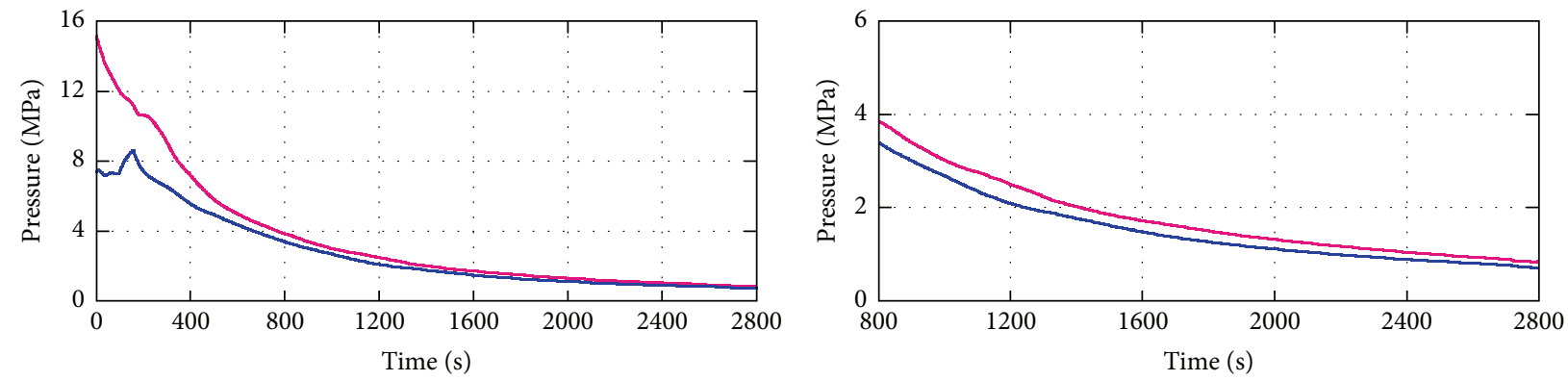

- Primary (cal. $\left.C_{d}=0.45\right)$

- Secondary-A (cal. $\left.C_{d}=0.45\right)$

- Primary (cal. $C_{d}=0.45$ )

— Secondary-A (cal. $\left.C_{d}=0.45\right)$
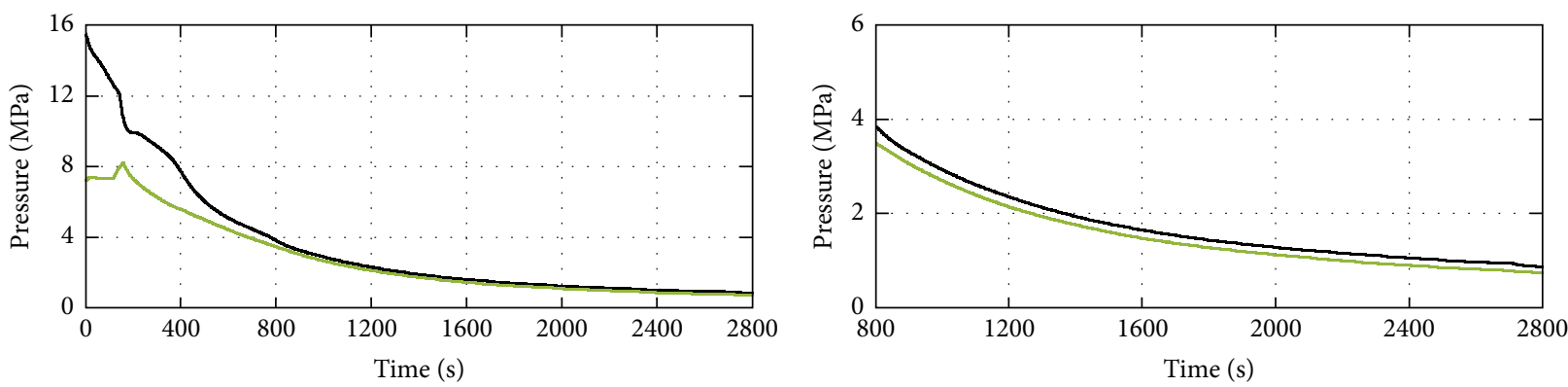

- Primary (exp.) Secondary-A (exp.)

(a) Overall transient (0-2800 s)

- Primary (exp.) Secondary-A (exp.)

(b) Local transient (800-2800s)

FIGURE 21: LSTF and RELAP5 results for primary and SG secondary pressures in loop-A in case of no release of dissolved gas.

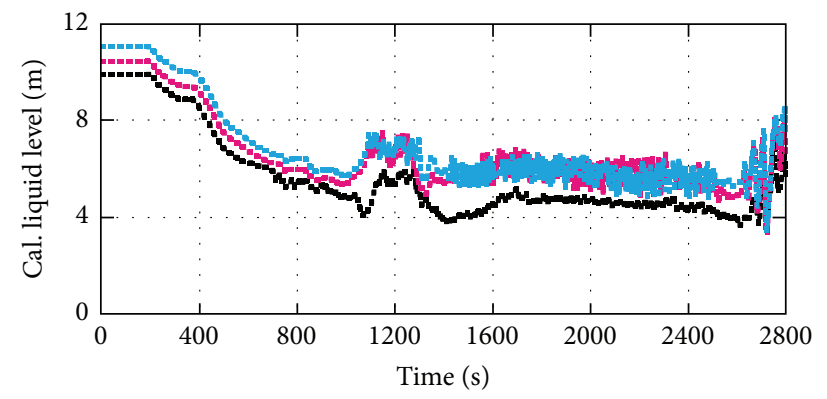

- - Short tube (cal. $\left.C_{d}=0.45\right)$

- - Medium tube (cal. $C_{d}=0.45$ )

- - - Long tube (cal. $C_{d}=0.45$ )

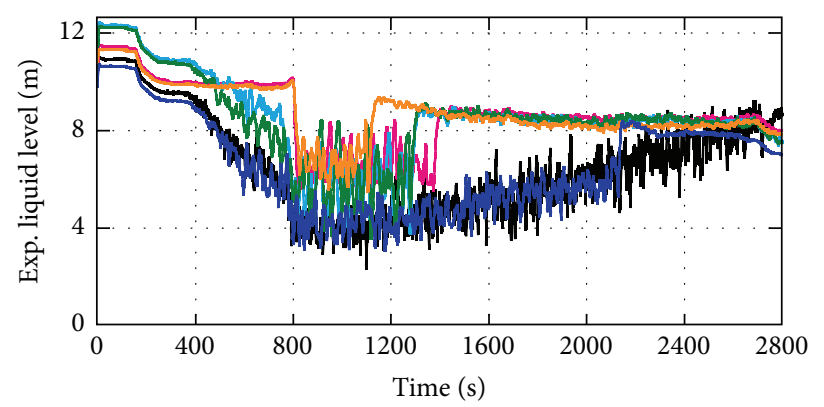

$\begin{array}{ll}\text { Tube } 1 \text { (exp.) } & \text { - Tube } 4 \text { (exp.) } \\ \text { Tube } 2 \text { (exp.) } & \text { Tube } 5 \text { (exp.) } \\ \text { Tube } 3 \text { (exp.) } & \text { Tube } 6 \text { (exp.) }\end{array}$

FIGURE 22: LSTF and RELAP5 results for SG U-tube upflow side collapsed liquid level in loop-A in case of no release of dissolved gas. 


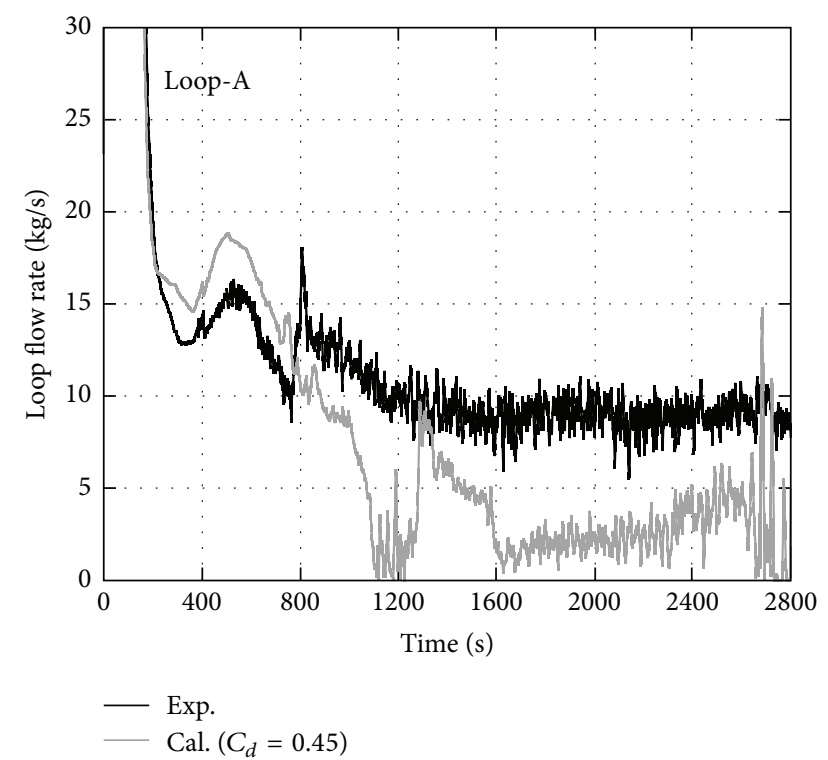

FIgURE 23: LSTF and RELAP5 results for primary loop flow rate in loop-A in case of no release of dissolved gas.

injection and two-phase NC. The actuation of LPI system contributed to long-term core cooling.

(2) The RELAP5 code predicted most of the overall trends of the major thermal-hydraulic responses after adjusting a break discharge coefficient for two-phase discharge flow under the assumption of releasing all the dissolved gas at the vessel upper plenum. The RELAP5 code, however, has remaining problems in the predictions of the cold leg liquid level, the SG U-tube collapsed liquid levels, and the primary loop flow rate. The RELAP5 posttest analysis showed that the dissolved gas accumulates in the SG U-tubes, similar to the estimation based on the measured data obtained from the LSTF test.

\section{Nomenclature}

\begin{tabular}{|c|c|}
\hline ACC: & Accumulator \\
\hline$C_{d}:$ & Break discharge coefficient \\
\hline$C_{R}:$ & $\begin{array}{l}\text { Initial relative mean concentration of } \\
\text { dissolved nitrogen gas }\end{array}$ \\
\hline$C_{S}:$ & $\begin{array}{l}\text { Initial mean concentration of dissolved } \\
\text { nitrogen gas }\end{array}$ \\
\hline$C_{T}:$ & $\begin{array}{l}\text { Saturated concentration of dissolved } \\
\text { nitrogen gas }\end{array}$ \\
\hline ECCS: & Emergency core cooling system \\
\hline$H:$ & Henry's law constant \\
\hline LPI: & Low-pressure injection \\
\hline LSTF: & Large scale test facility \\
\hline$M_{S}:$ & Sampled water mass \\
\hline NC: & Natural circulation \\
\hline$P:$ & Cover gas pressure \\
\hline PWR: & Pressurized water reactor \\
\hline ROSA: & Rig of safety assessment \\
\hline
\end{tabular}

SG: Steam generator

$T$ : Water temperature

$V_{S}$ : Amount of sampled gas.

\section{Competing Interests}

The authors declare that there are no competing interests regarding the publication of this paper.

\section{Acknowledgments}

This work was performed by using the LSTF test data obtained from contracts among the Kansai Electric Power Co., Inc., Hokkaido Electric Power Co., Inc., Shikoku Electric Power Co., Inc., Kyushu Electric Power Co., Inc., and the Japan Atomic Power Company, the Institute of Applied Energy, and Mitsubishi Heavy Industries, Ltd. as part of the "Safety Enhancement for LWRs" subsidy program developed by the Agency for Natural Resources and Energy. The authors would like to thank Messrs. M. Ogawa and A. Ohwada of Japan Atomic Energy Agency for performing the LSTF tests under collaboration with members from Nuclear Engineering Co. as well as Miss K. Toyoda of Research Organization for Information Science and Technology for manipulating the test data.

\section{References}

[1] T. Morimoto, A. Ohnuki, and H. Nishi, "Study on PWR safety system using SG secondary-side depressurization," in Proceedings of the 10th International Topical Meeting on Nuclear Thermal-Hydraulics, Operation and Safety (NUTHOS-10 '14), Okinawa, Japan, December 2014.

[2] H. Asaka and Y. Kukita, "Intentional depressurization of steam generator secondary side during a PWR small-break loss-ofcoolant accident," Journal of Nuclear Science and Technology, vol. 32, no. 2, pp. 101-110, 1995.

[3] H. Asaka, Y. Anoda, Y. Kukita, and I. Ohtsu, "Secondaryside depressurization during PWR cold-leg small break LOCAs based on ROSA-V/LSTF experiments and analyses," Journal of Nuclear Science and Technology, vol. 35, no. 12, pp. 905-915, 1998.

[4] The ROSA-V Group, "ROSA-V large scale test facility (LSTF) system description for the third and fourth simulated fuel assemblies," JAERI-Tech 2003-037, Japan Atomic Energy Research Institute, Ibaraki, Japan, 2003.

[5] T. Takeda, A. Ohnuki, and H. Nishi, "RELAP5 code study of ROSA/LSTF experiments on PWR safety system using steam generator secondary-side depressurization," Journal of Energy and Power Engineering, vol. 9, no. 5, pp. 426-442, 2015.

[6] T. Takeda, "RELAP5 analyses of ROSA/LSTF experiments on AM measures during PWR vessel bottom small-break LOCAs with gas inflow," International Journal of Nuclear Energy, vol. 2014, Article ID 803470, 17 pages, 2014.

[7] T. Shiraishi and H. Watakabe, "Development of the advanced accumulator for the pressurized water reactor," Nuclear Engineering and Design, vol. 249, pp. 318-334, 2012.

[8] T. Yonomoto, M. Kondo, and Y. Kukita, "PWR small break lossof-coolant-accident experiment at ROSA-V/LSTF with a combination of secondary-side depressurization and gravity-driven 
safety injection," Journal of Nuclear Science and Technology, vol. 34, no. 6, pp. 571-581, 1997.

[9] T. Yonomoto, I. Ohtsu, and Y. Anoda, "Thermal-hydraulic characteristics of a next-generation reactor relying on steam generator secondary side cooling for primary depressurization and long-term passive core cooling," Nuclear Engineering and Design, vol. 185, no. 1, pp. 83-96, 1998.

[10] W.-S. Yeung and R. K. Sundaram, "Effect of nitrogen release from accumulators on PWR LOCA analysis," in Proceedings of the 10th International Conference on Nuclear Engineering (ICONE-10 '02), pp. 123-129, Arlington, Va, USA, April 2002.

[11] C. Sarrette and D. Bestion, "Study of release of nitrogen gas dissolved in water during depressurisation-application to primary circuit of PWR," Nuclear Engineering and Design, vol. 224, no. 3, pp. 337-358, 2003.

[12] M. Hänninen and E. Ahtinen, "Simulation of non-condensable gas flow in two-fluid model of APROS-description of the model, validation and application," Annals of Nuclear Energy, vol. 36, no. 10, pp. 1588-1596, 2009.

[13] Y. Kukita, T. Yonomoto, H. Asaka et al., "ROSA/AP600 testing: facility modifications and initial test results," Journal of Nuclear Science and Technology, vol. 33, no. 3, pp. 259-265, 1996.

[14] RELAP5 Code Development Team, "RELAP5/MOD3 code manual," Tech. Rep. NUREG/CR-5535 (INEL-95/0174), Idaho National Engineering Laboratory, 1995.

[15] N. Zuber, "Problems in modeling small break LOCA," USNRC Report NUREG-0724, 1980.

[16] D. M. Himmelblau, "Solubilities of inert gases in water $0^{\circ} \mathrm{C}$. to near the critical point of water," Journal of Chemical and Engineering Data, vol. 5, no. 1, pp. 10-15, 1960.

[17] H. Asaka, Y. Kukita, T. Yonomoto, Y. Koizumi, and K. Tasaka, "Results of $0.5 \%$ cold-leg small-break LOCA experiments at ROSA-IV/LSTF: effect of break orientation," Experimental Thermal and Fluid Science, vol. 3, no. 6, pp. 588-596, 1990.

[18] H. K. Fauske, "The discharge of saturated water through tubes," Chemical Engineering and Progress Symposium Series, vol. 61, no. 59, pp. 210-216, 1965.

[19] K. H. Ardron and R. A. Furness, "A study of the critical flow models used in reactor blowdown analysis," Nuclear Engineering and Design, vol. 39, no. 2-3, pp. 257-266, 1976.

[20] D. W. Sallet, "Thermal hydraulics of valves for nuclear applications," Nuclear Science and Engineering, vol. 88, no. 3, pp. 220244, 1984.

[21] Susyadi and T. Yonomoto, "Analysis on non uniform flow in steam generator during steady state natural circulation cooling," JAERI-Research 2005-011, Japan Atomic Energy Research Institute, Ibaraki, Japan, 2005.

[22] T. Takeda, H. Asaka, and H. Nakamura, "RELAP5 analysis of OECD/NEA ROSA project experiment simulating a PWR lossof-feedwater transient with high-power natural circulation," Science and Technology of Nuclear Installations, vol. 2012, Article ID 957285, 15 pages, 2012.

[23] Y. Kukita, H. Nakamura, K. Tasaka, and C. Chauliac, "Nonuniform steam generator U-tube flow distribution during natural circulation tests in ROSA-IV large scale test facility," Nuclear Science and Engineering, vol. 99, no. 4, pp. 289-298, 1988.

[24] M. M. Shah, "A general correlation for heat transfer during film condensation inside pipes," International Journal of Heat and Mass Transfer, vol. 22, no. 4, pp. 547-556, 1979.

[25] W. A. Nusselt, "The surface condensation of water vapor," Zeitschrift des Vereines Deutscher Ingenieure, vol. 60, pp. 541546, 1916.
[26] K. M. Vierow and V. E. Schrock, "Condensation in a natural circulation loop with non-condensable gases, part I-heat transfer," in Proceedings of the International Conference on Multiphase Flows, Ibaraki, Japan, September 1991. 

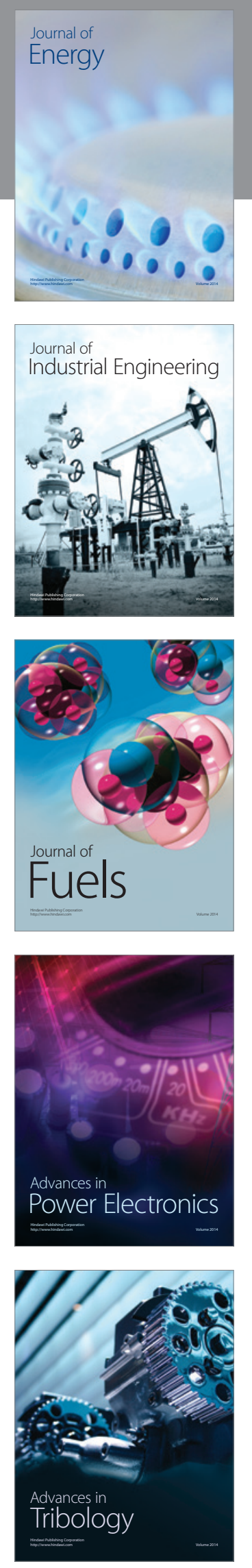
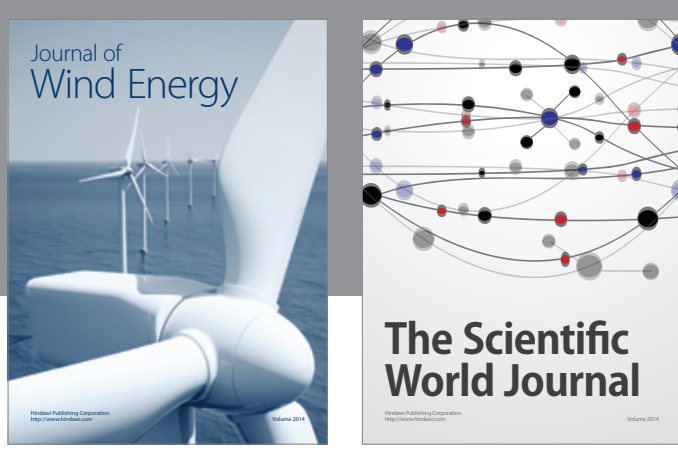

The Scientific World Journal
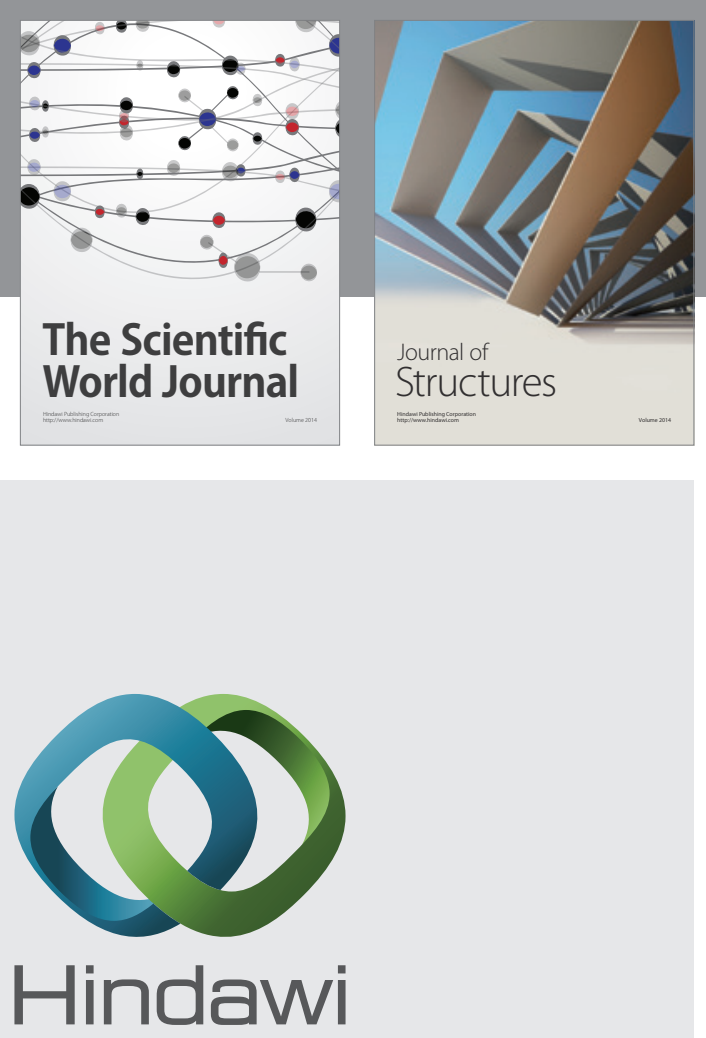

Submit your manuscripts at

http://www.hindawi.com
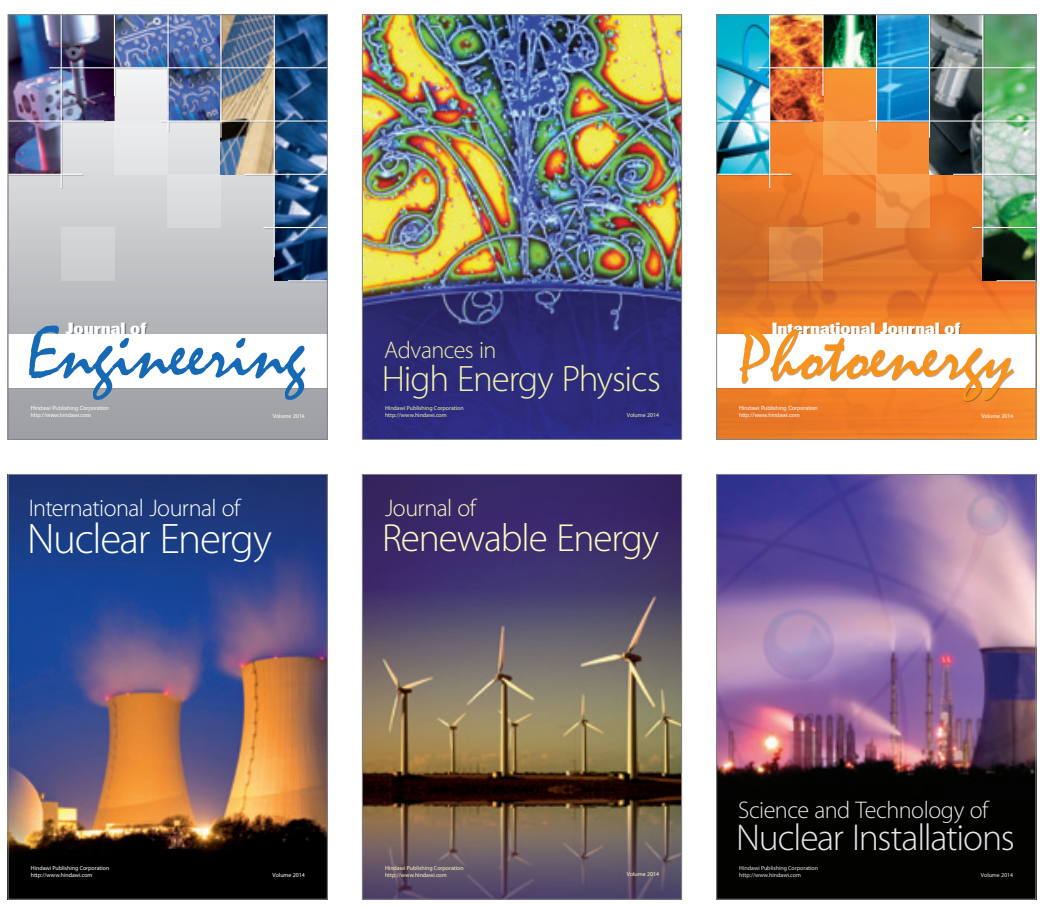
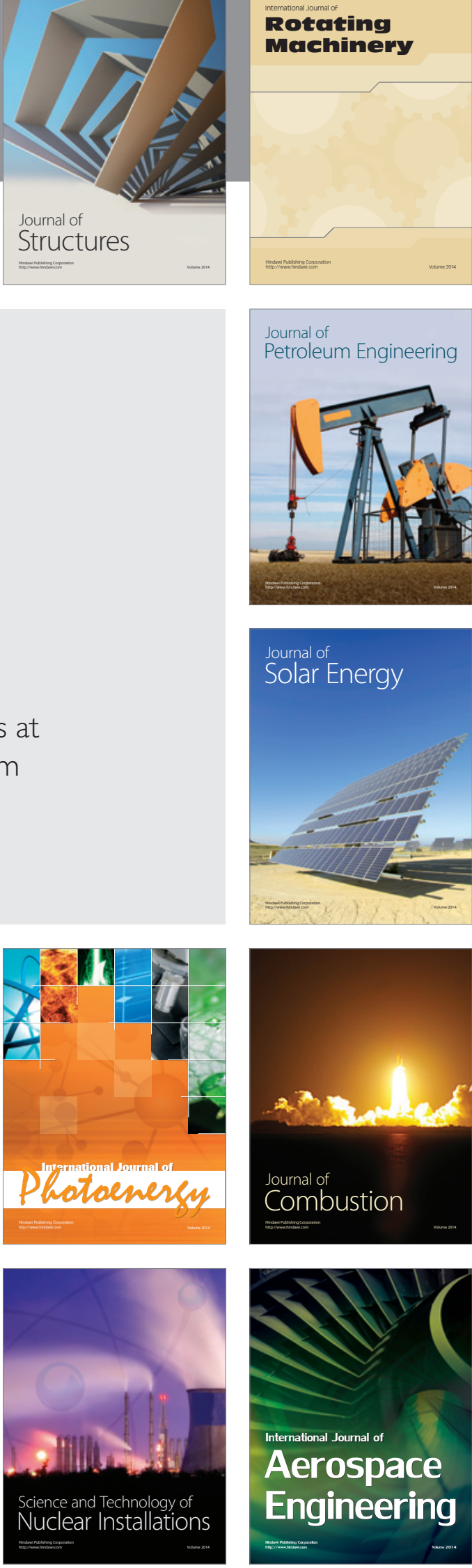